\title{
Promises and pitfalls of targeted agents in chronic lymphocytic leukemia
}

\author{
Thomas E. Lew ${ }^{1,2}$, Mary Ann Anderson ${ }^{1,2}$, John F. Seymour ${ }^{1,3}$ \\ 'Department of Clinical Haematology, The Royal Melbourne Hospital and Peter MacCallum Cancer Centre, Parkville 3050, \\ Australia. \\ ${ }^{2}$ Blood Cells and Blood Cancer Division, Walter and Eliza Hall Institute of Medical Research, Parkville 3050, Australia. \\ ${ }^{3}$ Faculty of Medicine, Dentistry and Health Sciences, The University of Melbourne, Parkville 3050, Australia.
}

Correspondence to: Prof. John F. Seymour, Department of Haematology Peter MacCallum Cancer Centre \& Royal Melbourne Hospital, Melbourne 3050, Australia.E-mail: john.seymour@petermac.org

How to cite this article: Lew TE, Anderson MA, Seymour JF. Promises and pitfalls of targeted agents in chronic lymphocytic leukemia. Cancer Drug Resist2020;3:415-44. http://dx.doi.org/10.20517/cdr.2019.108

Received: 11 Nov 2019 First Decision: 7 Jan 2020 Revised: 19 Jan 2020 Accepted: 5 Feb 2020 Available online: 23 May 2020

Science Editor: Lee M. Graves Copy Editor: Jing-Wen Zhang Production Editor: Jing Yu

\begin{abstract}
Targeted agents have significantly improved outcomes for patients with chronic lymphocytic leukemia, particularly high-risk subgroups for whom chemoimmunotherapy previously offered limited efficacy. Two classes of agent in particular, the Bruton tyrosine kinase inhibitors (e.g., ibrutinib) and the B-cell lymphoma 2 inhibitor, venetoclax, induce high response rates and durable remissions in the relapsed/refractory and frontline settings. However, maturing clinical data have revealed promises and pitfalls for both agents. These drugs induce remissions and disease control in the majority of patients, often in situations where modest efficacy would be expected with traditional chemoimmunotherapy approaches. Unfortunately, in the relapsed and refractory setting, both agents appear to be associated with an inevitable risk of disease relapse and progression. Emerging patterns of resistance are being described for both agents but a common theme appears to be multiple sub-clonal drivers of disease progression. Understanding these mechanisms and developing effective and safe methods to circumvent the emergence of resistance will determine the longer-term utility of these agents to improve patients' quality and length of life. Rational drug combinations, optimised scheduling and sequencing of therapy will likely hold the key to achieving these important goals.
\end{abstract}

Keywords: Chronic lymphocytic leukemia, drug resistance, venetoclax, B-cell lymphoma 2, ibrutinib, bruton tyrosine kinase, idelalisib, phosphatidylinositol 3-kinase

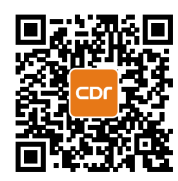




\section{INTRODUCTION}

Chronic lymphocytic leukemia (CLL) is the most common adult leukemia in the Western world, with approximately $\sim 20,100$ new cases estimated to be diagnosed in the USA in $2019^{[1]}$. The chemoimmunotherapy (CIT) era established fludarabine, cyclophosphamide and rituximab (FCR $)^{[2]}$ or bendamustine and rituximab $(\mathrm{BR})^{[3]}$ as the frontline regimens of choice for fit patients, achieving an objective response rate (ORR) of $\sim 90 \%$ and complete response rate (CRR) of 30\%-44\% with durable remissions among many responders. For patients with co-morbidities, frontline therapy with chlorambucilobinutuzumab achieves an ORR of $76 \%$ and CRR $22 \%$, with improved progression free survival (PFS) and overall survival (OS) compared to chlorambucil-rituximab or chlorambucil monotherapy ${ }^{[4-6]}$.

While the development of these effective CIT regimens marked a significant advance in the management of CLL, responses in patients whose disease harboured abnormalities in TP53 were less frequent and typically short-lived ${ }^{[7]}$, and the toxicity of the most efficacious regimens precluded their use in a high proportion of patients, given the advanced median age and frequent comorbidity at CLL diagnosis ${ }^{[8]}$. The PFS achieved with CIT regimens was also inferior for patients whose disease had unmutated immunoglobulin heavy chain variable region (IGHV) status ${ }^{[2,9-11]}$, reflecting a naïve B-cell originator cell with a more aggressive cancer biology ${ }^{[12,13]}$. These limitations were partially addressed by the advent of targeted agents, most significantly the Bruton tyrosine kinase (BTK) inhibitor ibrutinib ${ }^{[14]}$, the B-cell lymphoma 2 (BCL2) inhibitor venetoclax ${ }^{[15]}$ and the phosphatidylinositol 3-kinase (PI3K) inhibitor idelalisib ${ }^{[16]}$, which maintain response rates within TP53 aberrant and IGHV unmutated disease and have a favourable toxicity profile compared to CIT. Indeed, emerging data from Phase III trials have demonstrated superior PFS using targeted agent-based therapy over CIT in the frontline treatment of $\mathrm{fit}^{[17]}$ and elderly/comorbid patients ${ }^{[18-21]}$, and in the relapsed and refractory $(\mathrm{R} / \mathrm{R})$ setting $^{[22,23]}$. The precise therapeutic role and timing of these agents is likely to remain controversial given their cost, restricted geographic approvals and unclear benefit over CIT for fit young patients with IGHV mutated disease ${ }^{[1720,24]}$, in whom longer-term outcomes after frontline FCR are particularly favourable with $>50 \%$ PFS at 12.8 years median follow up ${ }^{[25]}$. Nevertheless, targeted agent-based therapy seems certain to emerge as the most efficacious treatment for most patients with CLL, offering deliverable and effective therapy to those previously unable to reap the benefits of CIT. Despite their advantages, the ultimate utilisation of these therapies in a global context will be restrained by funding limitations ${ }^{[26]}$. Moreover, the longer-term efficacy of novel agents is unfortunately compromised by the relentless development of resistant disease when used in the relapsed and refractory setting ${ }^{[27,28]}$. Further investigation is required to determine the optimal combinations, schedules and sequencing to maximise outcome, as well as the best strategies to prevent or treat emergent resistant disease.

In this review, we explore the promises and pitfalls of the three most established targeted agents: venetoclax, BTK inhibitors and PI3K inhibitors [Figure 1]. We outline their mechanism of action, therapeutic potential, drawbacks in clinical use and what is currently known regarding their resistance mechanisms. Richter transformation is a common mechanism of resistance with a unique pathobiology ${ }^{[29]}$, predominantly occurring within 1-2 years of commencement of Phase I/II trials among cohorts enriched for high risk and heavily pre-treated disease ${ }^{[30,31]}$. As this topic has been well reviewed recently elsewhere ${ }^{[29]}$, here we focus on the resistance mechanisms of progressive CLL that foil the promise of targeted therapy.

\section{VENETOCLAX}

\section{Mechanism}

Venetoclax (ABT-199/GDC-0199) is an orally bioavailable small molecule BCL2 homology domain (BH) 3-only protein mimetic which selectively inhibits the pro-survival protein $\mathrm{BCL} 2^{[32]}$. BCL2 is constitutively overexpressed in CLL cells and confers resistance to apoptosis by binding to and disabling BCL2 homology domain 3 (ВН3)-only proteins, which are instigators of the intrinsic cell death pathway ${ }^{[3,34]}$. When it binds 


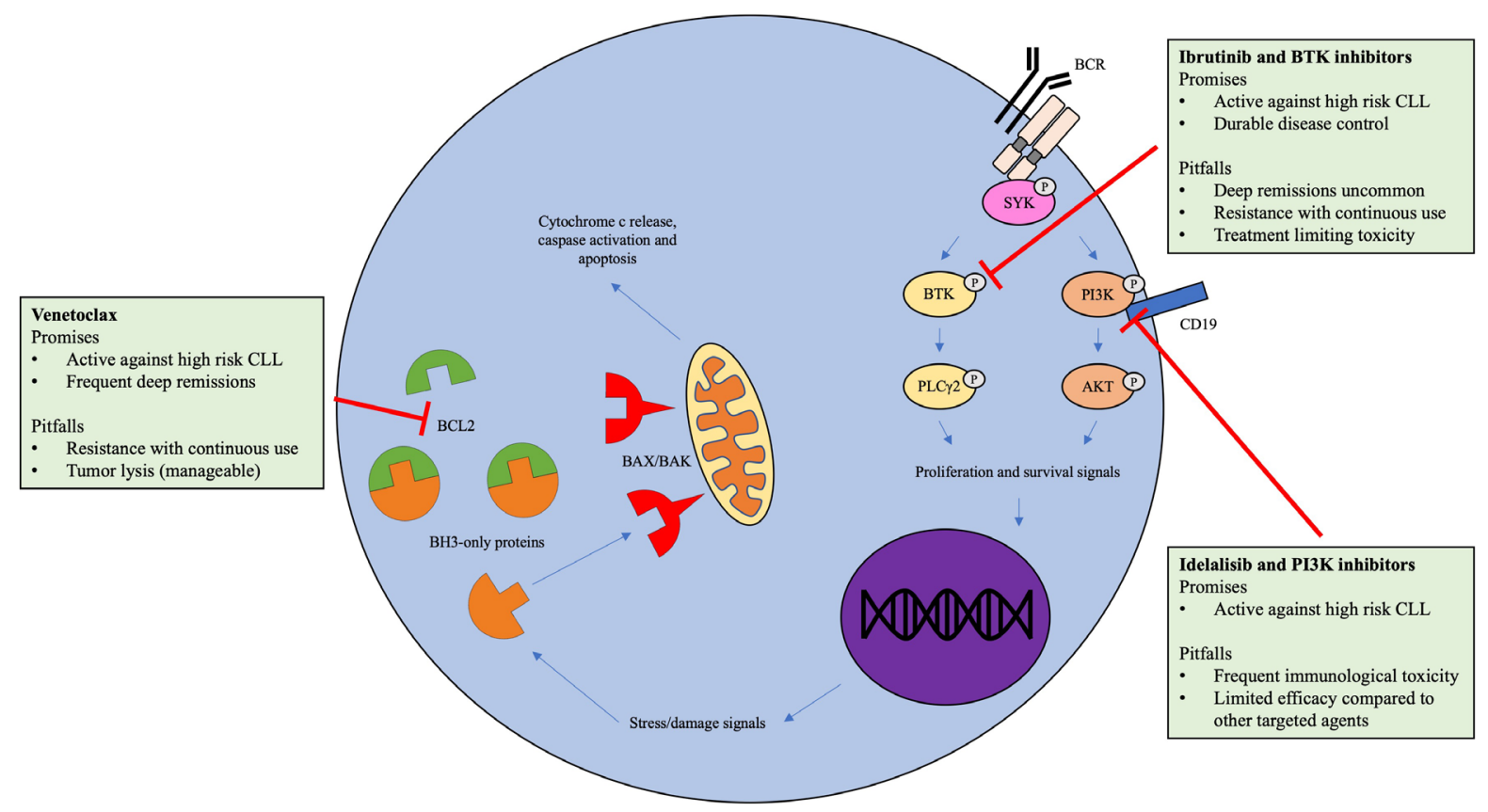

Figure 1. Target agents in chronic lymphocytic leukemia. AKT: v-akt murine thymoma viral oncogene; PI3K: phosphatidylinositol 3-kinase; SYK: spleen tyrosine kinase; BTK: bruton tyrosine kinase; BCR: B-cell receptor; BCL2: B-cell lymphoma 2; CLL: chronic lymphocytic leukemia; BAK: BCL2 homologous antagonist killer; $B A X: B C L 2$ associated $X ; B H 3: B C L 2$ homology domain 3

to BCL2 within CLL cells, venetoclax liberates BH3-only proteins from BCL2 sequestration, inducing BCL2 homologous antagonist killer/BCL2 associated X (BAK/BAX) protein mediated mitochondrial permeabilisation and cellular apoptosis ${ }^{[35]}$, independent of p53 function ${ }^{[36]}$. The selectivity of venetoclax for BCL2 was an advance on the therapeutic index of its predecessor, navitoclax (ABT-263), whose demonstrated efficacy in R/R CLL was compromised by dose limiting thrombocytopenia due to on target inhibition of another BCL2 family protein, B-cell lymphoma-extra large (BCL- $\mathrm{X}_{\mathrm{L}}$ ), which controls physiologic platelet lifespan ${ }^{[32,37]}$. Consistent with an in vitro p53-independent mechanism of cytotoxicity, venetoclax demonstrated a high rate of responses in patients whose disease harboured del(17p), leading to initial US Food and Drug Administration (FDA) approval in 2016 for this high-risk subgroup ${ }^{[38]}$. Based on recently published Phase III trials, venetoclax is now FDA approved for fixed duration therapy in R/ $\mathrm{R}$ disease in combination with rituximab ${ }^{[22]}$, and as frontline therapy for patients with comorbidities in combination with obinutuzumab ${ }^{[21]}$. Now an established therapeutic option in the treatment of CLL, questions remain regarding the optimal duration and scheduling of venetoclax therapy, appropriate sequencing and combinations with other agents, and the prevention and treatment of resistant disease.

\section{Promises}

The major advantages of venetoclax include its high response rates, even in traditionally high-risk subgroups, and its capacity to induce deep remissions, including undetectable measurable residual disease negative (uMRD) status ( $<1$ CLL cell per $10^{4}$ leukocytes by allele-specific oligonucleotide polymerase chain reaction or multiparameter flow cytometry ${ }^{[39-41]}$ ), with associated prolonged PFS and the option of time limited treatment [Table 1].

In the first-in-human and subsequently expanded Phase I trial, venetoclax achieved an ORR/CRR of $79 \% / 20 \%$ in heavily pre-treated patients (median lines of prior therapy 3 , range 1-11). MRD assessment was not protocol-specified and limited in application to patients who achieved a complete remission (CR), confirming bone marrow (BM) uMRD status in $5 \%$ of the total population, proving 
Table 1. Phase I/II and III trials of venetoclax \pm anti-CD20 monoclonal antibodies

\begin{tabular}{|c|c|c|c|c|}
\hline Study & Cohort & ORR/CRR MRD & PFS/OS & III/IV toxicity (> 10\%) \\
\hline \multicolumn{5}{|l|}{ Phase I/II } \\
\hline $\begin{array}{l}\text { Roberts et al. }{ }^{[15]} \\
\text { NCT01328626 } \\
\text { (venetoclax monotherapy*) }^{\star}\end{array}$ & $\begin{array}{l}\mathrm{R} / \mathrm{R} \\
\text { Dose finding }(n=56) \\
\text { Expansion }(n=60)\end{array}$ & $\begin{array}{l}79 \% / 20 \% \\
\text { BM flow cytometry- } \\
\text { neg 5\% }\end{array}$ & $\begin{array}{l}66 \% \text { PFS at } 15 \text { months } \\
84 \% \text { OS at } 24 \text { months }\end{array}$ & $\begin{array}{l}3 \text { cases clinical TLS, one fatal } \\
\text { Neutropenia } 41 \% \\
\text { Anemia } 12 \% \\
\text { Thrombocytopenia } 12 \%\end{array}$ \\
\hline $\begin{array}{l}\text { Stilgenbauer et al. }{ }^{[38,42]} \\
\text { NCT01889186 } \\
(\text { venetoclax monotherapy*) }\end{array}$ & $\begin{array}{l}\operatorname{del}(17 p) \\
\text { R/R }(n=158) \\
\text { TN }(n=5)\end{array}$ & $\begin{array}{l}77 \% / 20 \% \\
\text { PB uMRD } 30 \% \\
\text { BM uMRD } 13 \%\end{array}$ & $\begin{array}{l}54 \% \text { PFS at } 24 \text { months } \\
73 \% \text { OS at } 24 \text { months }\end{array}$ & $\begin{array}{l}\text { No clinical TLS } \\
\text { Neutropenia } 40 \% \\
\text { Anemia } 15 \% \\
\text { Thrombocytopenia } 15 \% \\
\text { Pneumonia } 10 \%\end{array}$ \\
\hline $\begin{array}{l}\text { Seymour et } a]^{[43,44]} \\
\text { NCT01682616 } \\
\left(\text { venetoclax }^{\wedge} \text { - rituximab }{ }^{+}\right)\end{array}$ & $\mathrm{R} / \mathrm{R}(n=49)$ & $\begin{array}{l}86 \% / 53 \% \\
\text { BM uMRD 57\% }\end{array}$ & $\begin{array}{l}56 \% \text { PFS at } 5 \text { years } \\
89 \% \text { OS at } 5 \text { years }\end{array}$ & $\begin{array}{l}2 \text { cases clinical TLS, one fatal } \\
\text { Neutropenia } 53 \% \\
\text { Anemia } 14 \% \\
\text { Thrombocytopenia } 16 \% \\
\text { Febrile neutropenia } 12 \% \\
\text { Infections and infestations } 16 \%\end{array}$ \\
\hline $\begin{array}{l}\text { Coutre et al. }{ }^{[45]} \\
\text { NCT02141282 } \\
\text { (venetoclax monotherapy*) }\end{array}$ & $\begin{array}{l}\text { IDEL pre-treated } \\
(n=36)\end{array}$ & $\begin{array}{l}67 \% / 8 \% \\
\text { PB uMRD 22\% } \\
\text { BM uMRD 6\% }\end{array}$ & $\begin{array}{l}79 \% \text { PFS at } 12 \text { months } \\
94 \% \text { OS at } 12 \text { months }\end{array}$ & $\begin{array}{l}\text { No clinical TLS } \\
\text { Neutropenia 50\% } \\
\text { Thrombocytopenia } 25 \% \\
\text { Anemia } 17 \%\end{array}$ \\
\hline $\begin{array}{l}\text { Jones et } a l^{[46]} \\
\text { NCT02141282 } \\
\text { (venetoclax monotherapy*) }\end{array}$ & IBR pre-treated $(n=91)$ & $\begin{array}{l}65 \% / 9 \% \\
\text { PB uMRD 26\% } \\
\text { BM uMRD 5\% }\end{array}$ & $\begin{array}{l}\text { Median PFS } 25 \text { months } \\
92 \% \text { OS at } 12 \text { months }\end{array}$ & $\begin{array}{l}2 \text { cases laboratory TLS } \\
\text { Neutropenia } 51 \% \\
\text { Anemia } 29 \% \\
\text { Thrombocytopenia 29\% } \\
\text { Lymphopenia } 1 \% \\
\text { Febrile neutropenia } 11 \%\end{array}$ \\
\hline $\begin{array}{l}\text { Flinn et al. }{ }^{[47]} \\
\text { NCT01685892 } \\
\text { (venetoclax }^{\alpha}- \\
\text { obinutuzumab }\end{array}$ & $\begin{array}{l}\mathrm{R} / \mathrm{R}(n=50) \\
\mathrm{TN}(n=32)\end{array}$ & $\begin{array}{l}\text { R/R } \\
95 \% / 37 \% \\
\text { PB uMRD 64\% } \\
\text { BM uMRD 62\% } \\
\text { TN } \\
100 \% / 78 \% \\
\text { PB uMRD } 91 \% \\
\text { BM uMRD } 78 \%\end{array}$ & $\begin{array}{l}\text { R/R } \\
85 \% \text { PFS at } 24 \text { months } \\
\text { OS NA } \\
\text { TN } \\
91 \% \text { PFS at } 24 \text { months } \\
\text { OS NA }\end{array}$ & $\begin{array}{l}\text { Neutropenia 53\%-58\% } \\
\text { Thrombocytopenia } 22 \% \\
\text { Infection } 13 \%-29 \%\end{array}$ \\
\hline \multicolumn{5}{|l|}{ Phase III } \\
\hline $\begin{array}{l}\text { Seymour et } a{ }^{[22,48,49]} \\
\text { MURANO } \\
\text { NCT02005471 }\end{array}$ & $\begin{array}{l}\mathrm{R} / \mathrm{R} \\
\mathrm{VEN}+\mathrm{R}(n=194)\end{array}$ & $\begin{array}{l}93 \% / 27 \% \\
\text { PB uMRD 62\% } \\
\text { BM uMRD 56\% }\end{array}$ & $\begin{array}{l}57 \% \text { PFS at } 4 \text { years } \\
85 \% \text { OS at } 4 \text { years }\end{array}$ & $\begin{array}{l}\text { TLS 3\%, } 1 \text { case clinical TLS } \\
\text { Neutropenia } 58 \% \\
\text { Infection } 18 \%\end{array}$ \\
\hline $\begin{array}{l}\text { (venetoclax }{ }^{\alpha} \text {-rituximab }{ }^{+} v s . \\
\text { bendamustine-rituximab) }\end{array}$ & $\mathrm{BEN}+\mathrm{R}(n=195)$ & $\begin{array}{l}68 \% / 8 \% \\
\text { PB uMRD 13\% } \\
\text { BM uMRD } 2 \%\end{array}$ & $\begin{array}{l}5 \% \text { PFS at } 4 \text { years } \\
67 \% \text { OS at } 4 \text { years }\end{array}$ & $\begin{array}{l}\text { TLS 1\%, } 1 \text { case clinical TLS } \\
\text { Neutropenia 39\% } \\
\text { Infection } 22 \%\end{array}$ \\
\hline $\begin{array}{l}\text { Fischer et al. } .^{[20,21,50]} \\
\text { CLL14 } \\
\text { NCT02242942 } \\
\text { (venetoclax }^{\delta}-\end{array}$ & $\begin{array}{l}\text { TN } \\
\mathrm{CIRS}>6 \text { or } \mathrm{CrCl}<70 \\
\mathrm{~mL} / \mathrm{min} \\
\mathrm{VEN}+\mathrm{G}(n=216)\end{array}$ & $\begin{array}{l}85 \% / 50 \% \\
\text { PB uMRD 76\% } \\
\text { BM uMRD } 57 \%\end{array}$ & $\begin{array}{l}88 \% \text { PFS at } 24 \text { months } \\
92 \% \text { OS at } 24 \text { months }\end{array}$ & $\begin{array}{l}3 \text { cases lab TLS } \\
\text { Neutropenia } 53 \% \\
\text { Infection } 18 \%\end{array}$ \\
\hline $\begin{array}{l}\text { obinutuzumab } \# \\
\text { vs. Chlorambucil- } \\
\text { obinutuzumab) }\end{array}$ & $\mathrm{CLB}+\mathrm{G}(n=216)$ & $\begin{array}{l}71 \% / 23 \% \\
\text { PB uMRD 35\% } \\
\text { BM uMRD } 17 \%\end{array}$ & $\begin{array}{l}64 \% \text { PFS at } 24 \text { months } \\
93 \% \text { OS at } 24 \text { months }\end{array}$ & $\begin{array}{l}5 \text { cases lab TLS } \\
\text { Neutropenia } 48 \% \\
\text { Infection } 15 \%\end{array}$ \\
\hline
\end{tabular}

${ }^{*}$ Continuous therapy until progression, death or other reason to withdraw from trial; ' continuous venetoclax therapy, cessation permitted in good response at clinician discretion; 'continuous venetoclax for patients with relapse and refractory disease, fixed duration therapy for 12 months in treatment naïve patients with optional additional 12 months of therapy if not in CR or BM uMRD response; ${ }^{+} 375 \mathrm{mg} / \mathrm{m}^{2}$ in Month 1, then $500 \mathrm{mg} / \mathrm{m}^{2}$ each month to a total of six cycles; ${ }^{*} 100 \mathrm{mg}$ on Day 1, $900 \mathrm{mg}$ on Day 2 (or $1000 \mathrm{mg}$ on Day 1), $1000 \mathrm{mg}$ on Day 8 and 1000 mg on Day 15 of Cycle 1, and subsequently 1000 mg each month to a total of six cycles; ${ }^{\alpha}$ venetoclax continued until progressive $\mathrm{CLL}$, unacceptable toxicity or two years total therapy; ${ }^{\delta}$ venetoclax continued until progressive CLL, unacceptable toxicity or one year total therapy. ORR: overall response rate; CRR: complete response rate; PFS: progression free survival; OS: overall survival; R/ R: relapsed and refractory; TN: treatment naïve; VEN: venetoclax; IDEL: idelalisib; IBR: ibrutinib; BEN: bendamustine; CLB: chlorambucil; R: rituximab; G: obinutuzumab; CIRS: cumulative illness rating scale; $\mathrm{CrCl}$ : creatinine clearance; PB uMRD: peripheral blood minimal

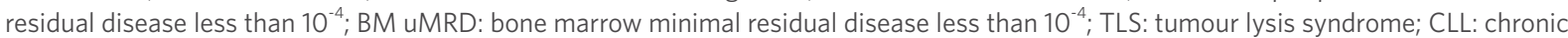
lymphocytic leukemia

the feasibility of attaining such deep responses in the R/R setting with targeted agent monotherapy. A consistent ORR of 70\%-80\% was observed in patients whose disease was fludarabine-refractory, bulky $(>5 \mathrm{~cm})$, IGHV unmutated and harbouring del(17p), with CRs observed in all subgroups ${ }^{[15]}$. 
The Phase II trial enrolling 158 patients with R/R CLL harbouring del(17p) confirmed frequent, deep and durable responses in this subgroup with an ORR/CRR of $77 \% / 20 \%$, peripheral blood (PB) and BM uMRD rate of $30 \% / 13 \%$ and a 24 -month PFS of $50 \%{ }^{[42]}$. Encouraged by evidence of clinical synergy between rituximab and navitoclax ${ }^{[51,52]}$, the Phase Ib venetoclax-rituximab combination study achieved impressive depth of remission in R/R disease, with an ORR/CRR of 86\%/53\% and BM uMRD status in $61 \%$ of patients ${ }^{[43,44]}$. Sixteen patients ceased therapy in uMRD response, with four patients electively withdrawing from the study, 11 patients in ongoing response at a median of 33 (12-58) months off drug and one case of progressive disease at 38 months off therapy ${ }^{[43]}$. This finding, supported by the observation of consistently excellent PFS associated with uMRD remissions regardless of regimen utilised to attain that status from the CIT era ${ }^{[53-55]}$, spurred a new paradigm of time-limited targeted agent combination therapy pursuant of uMRD remission. The MURANO trial compared fixed duration venetoclax therapy for 24 months combined with six months of rituximab to standard CIT with six cycles of $\mathrm{BR}$ in patients with $\mathrm{R} / \mathrm{R}$ CLL, demonstrating significantly higher response rates, uMRD remissions in $\mathrm{PB}$ and BM, PFS and OS, with no increase in clinically significant toxicities ${ }^{[22,48,49]}$. Among the 83 patients who attained uMRD remissions, only two developed progressive disease at median of 10 months off therapy and $70 \%$ had maintained uMRD status, confirming an enduring benefit for patients who cease therapy in deep response $^{[49]}$. The CLL14 trial in patients with comorbidity or renal impairment combined obinutuzumab with 12 months of either venetoclax or chlorambucil, with increased depth and durability of response in the venetoclax-based treatment arm without additional toxicity, although no significant difference in OS was appreciable with short follow-up at the time of publication ${ }^{[2,21]}$. In both of these Phase III studies, the benefit of venetoclax-based therapy was maintained in both TP53 mutated and IGHV unmutated disease subsets.

Multiple reports have now confirmed an excellent PFS associated with uMRD attainment with venetoclaxbased therapy. Extended follow up of the MURANO and CLL14 trials demonstrated significantly improved PFS for patients who achieved uMRD responses ${ }^{[48-50]}$. Attainment of uMRD status was also associated with prolonged PFS among patients with disease bearing del(17p) treated with venetoclax monotherapy ${ }^{[42]}$. At median survivor follow up of five years, patients achieving uMRD remission with venetoclax monotherapy in Phase I/II trials at our institution had a $92 \%$ PFS at two years after attainment of uMRD status ${ }^{[5]}$.

Overall, venetoclax-based therapy outperforms CIT, especially for patients with traditional high-risk disease features. Venetoclax is distinguished from other targeted therapies by its capacity to induce deep remissions with prolonged PFS, rendering it an essential component of time-limited targeted therapy.

\section{Pitfalls}

Although the adverse effects of severe neutropenia and tumour lysis syndrome warrant careful prophylaxis and monitoring, these complications can be prevented or mitigated in the majority of cases. The more troubling pitfall of continuous venetoclax monotherapy, despite its efficacy, is the common emergence of resistant disease with extended follow up, even among many patients who attain UMRD.

Consistent with potent cytotoxicity in CLL, two fatalities due to clinical tumour lysis syndrome (TLS) were reported in the dose ramp-up of the Phase I/Ib studies of venetoclax ${ }^{[15,44]}$. In the Phase I expansion cohort of 60 patients, an extended step-wise dose escalation commencing at $20 \mathrm{mg} /$ day was adopted with a more intensive TLS prophylaxis and surveillance program, with only one case of laboratory TLS and no cases of clinical TLS ${ }^{[15]}$. Davids et al ${ }^{[57]}$ reported a detailed analysis of 166 patients managed with this step-wise dose escalation protocol and risk adapted TLS prevention and management strategy as per manufacturer guidelines ${ }^{[58]}$, identifying five cases of investigator assessed TLS, although none met formal Howard laboratory or clinical criteria ${ }^{[59]}$. Hyperphosphatemia was the most sensitive and earliest indictor of impending TLS. Dose interruptions were applied in four cases, with all patients ultimately 
resuming therapy and attaining the target dose of $400 \mathrm{mg} /$ day $^{[57]}$. Overall, although clinicians must remain vigilant to the risk of TLS, clinically significant sequelae are rare with the use of established risk adapted protocols. Grade III/IV neutropenia is relatively common, occurring in 37\% of patients, predominantly in the first 3-6 months of therapy; however, granulocyte colony stimulating factor treatment and occasional dose interruptions are effective in the majority of $\operatorname{cases}^{[57,60]}$. In Phase III trial data, febrile neutropenia was less common with venetoclax-rituximab compared with BR ( $4 \% v s .9 \%)$, as were aggregated Grade III/IV infections and infestations $(18 \% v \mathcal{~ s . ~} 22 \%)^{[22]}$. In CLL14, febrile neutropenia occurred in $5 \%$ of patients treated with venetoclax-obinutuzumab compared to $4 \%$ with chlorambucil-obinutuzumab, with infections and infestations occurring in $18 \%$ and $15 \%$, respectively ${ }^{[21]}$. Although common, venetoclax related neutropenia is typically transient and manageable, and venetoclax-based therapies have comparable infective risk to CIT regimens.

Given the manageable nature of the most common major toxicities, the development of resistant disease with continuous monotherapy emerges as a more challenging threat to patients receiving venetoclax treatment. In the earliest description of progression on venetoclax, fludarabine-refractoriness and complex karyotype ( $\geq 3$ aberrations on conventional metaphase analysis) were the dominant associations with earlier progression in heavily pre-treated, high risk patients receiving venetoclax in Phase I/II clinical trials, although these observations were predominantly driven by early Richter transformation events and may be less relevant to standard risk patients ${ }^{[30]}$. In a pooled retrospective analysis of four Phase I/ II trials in patients with R/R CLL, inferior CRR and reduced duration of response was associated with a higher number of prior therapies (especially $>3$ ), prior B-cell receptor (BCR) pathway inhibitor therapy (especially if refractory) and bulky adenopathy ${ }^{[61]}$. As seen in the CIT era, depth of response by international workshop on CLL (iwCLL) criteria and clearance of MRD from the PB were significantly associated with prolonged PFS ${ }^{[42,56,61]}$. Patients whose disease harboured TP53 or NOTCH1 abnormalities had an inferior duration of response, despite initial response rates comparable to the overall cohort ${ }^{[61]}$. These mutations are also associated with inferior outcomes with ibrutinib treatment ${ }^{[62]}$. Supportive data from our institutional experience suggest that abnormalities in TP53 may be associated with an earlier time to recrudescence among patients with uMRD response ${ }^{[56]}$. Although venetoclax induces frequent and deep responses in patients whose disease harbours TP53 abnormalities, this subgroup appears to nevertheless maintain an increased risk of treatment resistance and disease progression. Overall, the majority of patients with $\mathrm{R} / \mathrm{R}$ CLL treated with continuous venetoclax monotherapy will ultimately progress at an estimated median of 37 (95\%CI: 30-42) months ${ }^{[6]}$. Although patients who attain a deep response have prolonged PFS, MRD recrudescence was common after 3-4-year follow up from attainment of uMRD remission in patients treated with continuous venetoclax monotherapy at our centres ${ }^{[56]}$. Overall, the emergence of resistant disease can be expected for the majority of patients with R/R CLL receiving continuous venetoclax monotherapy.

The mechanisms of venetoclax resistance remain incompletely understood. Primary resistance to venetoclax may be driven by the balance of $\mathrm{BH} 3$-only proteins, such as BCL-2-interacting mediator of cell death (BIM), and alternative BCL2 family proteins, such as MCL1 and BCL- $\mathrm{X}_{\mathrm{L}}$, as observed in in vitro data from myeloma cell lines and patients with resistant mantle cell lymphoma ${ }^{[63]}$. Clinical response to navitoclax inversely correlated with MCL1 expression in CLL cells, and was positively associated with higher expression of $\mathrm{BIM}^{[37]}$, a $\mathrm{BH} 3$-only protein that is liberated by BCL2 inhibition, neutralises MCL1 and directly activates $\mathrm{BAX} / \mathrm{BAK}{ }^{[64]}$. In vitro $\mathrm{CD} 40 \mathrm{~L}$ and $\mathrm{BCR}$ stimulation of CLL cells induces increased expression of BCL- $\mathrm{X}_{\mathrm{L}}$, Blf-1 and MCL1, with associated resistance to venetoclax, suggesting lymph node microenvironmental signalling may blunt the sensitivity of CLL cells to selective BCL2 inhibition. Preclinical models of microenvironment resistance also suggest that anti-CD20 monoclonal antibodies and BCR pathway inhibitors may deprive CLL cells of these pro-survival signals ${ }^{[65-67]}$, and may explain the higher rates of response and uMRD remission achieved by venetoclax-rituximab and venetoclax-ibrutinib 
combination regimens compared to historical results with venetoclax monotherapy ${ }^{[22,44,68,69]}$. Although direct head-to-head trials are not available and populations treated in the respective studies differed in a number of important prognostic factors, these combinations appear to enhance response rate and depth, potentially surmounting the primary resistance mechanisms that compromise responses to venetoclax monotherapy.

Insights into secondary (acquired) resistance to venetoclax are likely to mature with extended follow up. The best described mechanism of resistance is acquisition of the Gly101Val point mutation in BCL2, which was recently identified by Blombery et al. ${ }^{[28]}$ and has been independently confirmed ${ }^{[70]}$. This mutation is not detectable in pre-venetoclax CLL cells or other lymphoproliferative disorders ${ }^{[28,70]}$. The mutation was initially identified in seven out of 15 patients with progressive CLL on continuous venetoclax for R/R disease, including four patients with disease relapsing from uMRD remissions. in vitro studies confirmed a 180-fold reduction in venetoclax affinity for the Gly101Val mutated BCL2, with resultant resistance to apoptosis $^{[28]}$. The valine substitution disrupts engagement of the $\mathrm{P} 2$ binding pocket by venetoclax, while preserving the protein's capacity to sequester $\mathrm{BH} 3$-only proteins ${ }^{[7]}$. Although the Gly101Val mutation is clearly one recurrent mechanism of resistance, the variant allele frequency of the mutation at progression varied significantly (1.4\%-70\%), suggesting multiple sub-clones with distinct resistance mechanisms. Indeed, an alternative BCL2 mutation, Asp103Tyr, thought to also disrupt venetoclax engagement with the BCL2 binding site, was identified in addition to the Gly101Val harbouring subclone in one patient ${ }^{[70]}$. This mutation and several other newly identified ones (Asp103Glu, Arg107_Arg110dup and Val156Asp) have also been found to co-occur in 7/10 (70\%) patients with progressive disease bearing Gly101Val mutations at our centre, and exceed the variant allele frequency of Gly101Val in several cases. Nevertheless, all patients had significant subpopulations within their progressive CLL which did not harbour any BCL2 mutations, implying the presence of alternative simultaneous resistance mechanisms ${ }^{[72]}$. In one informative patient, a distinct subpopulation with increased BCL- $\mathrm{X}_{\mathrm{L}}$ expression was found to be mutually exclusive to the Gly101Val harbouring population, culminating in disproportionately high venetoclax resistance despite a modest Gly101Val allelic frequency. The mechanism of increased BCL- $\mathrm{X}_{\mathrm{L}}$ expression in these cells is unknown ${ }^{[28]}$. It is likely that numerous mutations and non-point-mutation resistance mechanisms will ultimately be identified in patients with progressive CLL on venetoclax. Another novel resistance mutation in the BCL2, Phe104Ile, has been recently described in relapsed follicular lymphoma after venetoclax treatment ${ }^{[73]}$. Amplification of chromosome 1q23, which harbours the loci for MCL1 and PRKAB2 (a regulator of mitochondrial metabolism), has been confirmed in three out of six patients with CLL relapsing on venetoclax. Correlative cell line data support MCL1 upregulation and enhanced mitochondrial oxidative phosphorylation as mechanisms of resistance to venetoclax ${ }^{[7]}$. Whole genome sequencing of eight patients with CLL prior to venetoclax therapy and at time of progression identified recurrent mutations in $B T G 1$ and homozygous deletion $C D K N 2 A / B$, as well as one patient each with a mutation in BRAF and amplification of PD-L1. BRAF $F^{V 600 E}$ transduced cell lines exhibited elevated MCL1 expression and in vitro venetoclax resistance, offering a potentially druggable target. Phylogenetic tree analysis based on the distribution of mutations indicated heterogenous patterns of clonal evolution which may give rise to concurrent, mechanistically independent resistant clones ${ }^{[75]}$.

Data on the treatment of venetoclax-resistant disease are currently immature. Anderson et al ${ }^{[30]}$ described ten patients with progressive CLL after venetoclax (including four cases after successful salvage of Richter transformation) treated with BTK inhibitor therapy, with objective responses in nine cases, although cohort follow up was short. Other groups have similarly reported responses to ibrutinib in small patient cohorts progressing after venetoclax therapy with limited follow up ${ }^{[76-80]}$. In a recent retrospective analysis of 188 patients receiving subsequent therapy after venetoclax, patients receiving BTK inhibitors had an estimated 24-month PFS of 78\%, with longer disease control in BTK inhibitor naïve patients. These outcomes compared to a median PFS of five months with PI3K inhibitors and nine months using chimeric antigen receptor (CAR) T cell therapy ${ }^{[78]}$. Allogenic stem cell transplantation may offer durable disease 
control for a selected group of patients $s^{[7,81]}$. Although ibrutinib appears to be a reasonable treatment for venetoclax-resistant disease, longer-term data are required to establish the ideal therapy for these patients. Re-treatment with venetoclax therapy may be an option after time-limited therapy. In four patients who progressed after ceasing venetoclax-rituximab therapy in good response (two MRD detectable CR and two UMRD CR), re-treatment with venetoclax \pm rituximab achieved two partial remissions (PRs) with ongoing response, one PR with progressive disease at 18 months and response status was not evaluable at last follow up for the fourth patient ${ }^{[43]}$. In fourteen patients with progressive disease after completing therapy in the MURANO trial, venetoclax-based retreatment achieved an OR in only two (14\%) cases $^{[48]}$, although the efficacy of retreatment may be different for patients whose disease progresses after ceasing therapy in deep remission compared to patients with progressive disease after suboptimal initial response. Extended follow up may clarify whether time-limited, MRD-guided therapy can minimise the selection of resistant clones and facilitate re-treatment with venetoclax-based therapy in some patients.

Taken together, these observations suggest that polyclonal resistance is likely the norm in progressive CLL on continuous venetoclax therapy, synchronously utilising BCL2 mutants, alternative BCL2 family proteins and as yet incompletely defined mechanisms. Open questions remain as to whether combination therapy can eradicate the population from which these resistant clones arise, whether time limited therapy will diminish the selection pressure that drives polyclonal resistance or indeed if these mutations may prove useful biomarkers of impending relapse and the need for treatment intensification. Our current understanding of venetoclax resistance is overwhelmingly derived from patients with $\mathrm{R} / \mathrm{R}$ disease heavily pre-treated in the chemoimmunotherapy era, and whether these observations will remain relevant in the frontline setting will require further investigation as the experience using venetoclax in treatment naïve (TN) patients matures.

\section{Summary: venetoclax}

We recommend venetoclax for two years combined with six cycles of rituximab for patients with R/ $\mathrm{R}$ disease, although ibrutinib is a reasonable alternative. For TN patients with comorbidity (cumulative illness rating score $>6$ ) or poor renal function (creatinine clearance $<70 \mathrm{~mL} / \mathrm{min}$ ), we recommend one year of venetoclax combined with six cycles of obinutuzumab, although ibrutinib \pm an anti-CD20 monoclonal antibody is also reasonable. Chlorambucil-obinutuzumab is a reasonable treatment for patients with comorbidities if the availability of novel agents is limited. For patients whose disease progresses on venetoclax, we recommend ibrutinib salvage therapy based on limited evidence, although such patients should ideally be enrolled in clinical trials. Among targeted therapies in CLL, venetoclax has the unique capacity to frequently induce uMRD remissions, especially when used in combination. Disease resistance is frequently observed with continuous monotherapy in the R/R setting, driving an argument for time-limited combination therapy pursuant of uMRD remission in current practice and future trials.

\section{IBRUTINIB}

\section{Mechanism}

Ibrutinib (PCI-32765) is an orally bioavailable, irreversible small molecule inhibitor of BTK, a member of the Tec kinase family, which is integral to the intracellular communication of BCR stimulation ${ }^{[82]}$. Inhibition of BTK disrupts downstream signalling pathways which enhance CLL cell survival, such as v-akt murine thymoma viral oncogene (AKT), extracellular receptor kinase (ERK) and Nuclear Factor kappalight-chain-enhancer of activated $\mathrm{B}$ cells $(\mathrm{NF}-\kappa \mathrm{B})^{[83-86]}$. CLL cells also require intact BTK function to home and adhere to lymphoid organs ${ }^{[87,88]}$, leading to peripheralization of malignant cells with ibrutinib treatment and deprivation of microenvironment survival signalling ${ }^{[89]}$. Extended follow up of Phase I/II studies has confirmed an ORR of $85 \%-95 \%$, including patients whose disease is heavily pre-treated, bulky, IGHV unmutated or bears del(17p)/TP53 mutations. Although early CR is uncommon, responses gradually 
deepen with up to $29 \%$ of patients still on therapy at four years ultimately attaining a $\mathrm{CR}^{[14,89-92]}$. The strategy of prolonged disease control without deep remission using continuous therapy has been validated in Phase III clinical trials, such that ibrutinib-based therapy has demonstrated superior PFS over CIT in frontline treatment for young ${ }^{[17]}$ and elderly/comorbid patients ${ }^{[18,19]}$, and in the R/R setting ${ }^{[23]}$, although an OS benefit has not been demonstrated in elderly cohorts. Ibrutinib is now FDA approved for the treatment of a broad population of patients with CLL, with and without anti-CD20 monoclonal antibodies; however, the benefit of combination with anti-CD20 therapy is unclear ${ }^{[19]}$. Although ibrutinib is undoubtedly a significant advance in the treatment of CLL, maturing experience with long-term continuous therapy has demonstrated challenges for deliverability ${ }^{[93]}$, and the emergence of resistant disease ${ }^{[27]}$.

\section{Promises}

Ibrutinib-based therapy can achieve long-term disease control for most patients with CLL, including patients with traditional high-risk features and advanced age, and may lead to a degree of immune reconstitution with extended use [Table 2].

In a Phase Ib/II study of 51 patients with heavily pre-treated CLL, ibrutinib achieved an initial ORR/CRR of $71 \% / 4 \%$, which increased to $89 \% / 10 \%$ on long-term follow up of an expanded cohort $(n=101)$. Despite infrequent CRs, the median PFS for this cohort was 51 months, with $60 \%$ OS at five years. Response rates were not compromised in patients with the traditional adverse risk factors of bulky disease, IGHV mutation, complex karyotype or TP53 abnormalities ${ }^{[14,89]}$. The promising efficacy of ibrutinib in patients whose disease harboured TP53 abnormalities was validated in the dedicated Phase II study of such patients, with an ORR/CRR of $98 \% / 29 \%$ at long-term follow up. Five-year PFS was $74 \%$ in TN patients, compared with $19 \%$ in patients with $\mathrm{R} / \mathrm{R}$ diseas $\mathrm{e}^{[90,91]}$. Pooled analysis of 230 patients with R/R CLL with $\operatorname{del}(17 \mathrm{p})$ treated with ibrutinib had similar results with an ORR/CRR of $85 \% / 10 \%$ and 30-month PFS of $57 \%{ }^{[94]}$. Overall, these observations compared favourably to frontline FCR for patients with disease bearing $\operatorname{del}(17 \mathrm{p})$, which achieved a median PFS of 14 months $(95 \% \mathrm{CI}: 10-18)^{[7]}$, and established ibrutinib as a treatment of choice in this high-risk population. Phase II data also suggested promising efficacy in 35 elderly patients ( $\geq 65$ years; $18 \mathrm{TN}, 17 \mathrm{R} / \mathrm{R}$ ), achieving an ORR/CRR of $98 \% / 27 \%$ on long-term follow up, with five-year PFS and OS of $81 \%$ and $84 \%$, respectively, and no cases of progression or death among TN patients ${ }^{[90]}$. Comparable response rates were observed in cohort of 31 TN patients aged $\geq 65$ years, with $>90 \%$ five-year PFS and $\mathrm{OS}^{[14,92]}$. These data challenged the outcomes previously attained with CIT, and endorsed ibrutinib as a promising option for patients for whom traditional therapy had been undeliverable or ineffective.

Phase III data now support the use of ibrutinib therapy for many of the common clinical scenarios encountered in the management of patients with CLL. Results from the RESONATE trial confirmed the markedly higher efficacy of ibrutinib over ofatumumab in patients with R/R CLL (ORR 91\% vs. 4\%; CRR $11 \%$ vs. $0 \%$, respectively) and a median PFS of 44 months vs. 8 months. This benefit was observed across all subgroups, including disease harbouring $\operatorname{del}(17 \mathrm{p})^{[23,95,96]}$. In elderly TN patients whose disease lacked del(17p), RESONATE 2 demonstrated the superiority of ibrutinib over chlorambucil in rate and depth of response, PFS and OS, without additional toxicity ${ }^{[97,98]}$. In the iLLUMINATE trial, elderly or comorbid patients were randomised to frontline combination therapy with ibrutinib-obinutuzumab or the previously most effective regimen in this population, chlorambucil-obinutuzumab. Ibrutinib-obinutuzumab showed superior efficacy in terms of ORR (91\% vs. $81 \%$ ), CRR (41\% vs. 16\%), PB uMRD attainment (30\% vs. 20\%) and PFS (79\%vs. $31 \%$ at 30 months). The PFS benefit was observed for all subgroups except in patients lacking any of del(17p), TP53 mutation, del(11q) or unmutated IGHV, although this sub-analysis was small $(n=23)$. No difference in OS has been observed at a median follow up of 31 months ${ }^{[18]}$. The ALLIANCE trial similarly demonstrated superior PFS with ibrutinib-based therapy compared to BR (87\% vs. $74 \%$ PFS at 24 months) in TN elderly patients, with no demonstrated OS benefit (90\%vs. 95\% OS at 24 months $)^{[19]}$. 
Table 2. Phase I/II and III trials of ibrutinib \pm anti-CD20 monoclonal antibodies

\begin{tabular}{|c|c|c|c|c|}
\hline Study & Cohort & ORR/CRR MRD & PFS/OS & III/IV toxicity (> 10\%) \\
\hline \multicolumn{5}{|l|}{ Phase I/II } \\
\hline $\begin{array}{l}\text { Byrd et al. }{ }^{[14,89]} \\
\text { NCT01105247 } \\
\text { (ibrutinib monotherapy) }\end{array}$ & $\begin{array}{l}\mathrm{R} / \mathrm{R} \\
(n=101)\end{array}$ & $89 \% / 10 \%$ & $\begin{array}{l}\text { Median PFS } 51 \text { months } \\
60 \% \text { OS at } 5 \text { years }\end{array}$ & $\begin{array}{l}\text { HTN 25\% } \\
\text { Pneumonia 27\% } \\
\text { Neutropenia 21\% } \\
\text { Thrombocytopenia } 11 \%\end{array}$ \\
\hline $\begin{array}{l}\text { O'Brien et al. }{ }^{[14,92]} \\
\text { NCT01105247 } \\
\text { (ibrutinib monotherapy) }\end{array}$ & $\begin{array}{l}\mathrm{TN} \geq 65 \text { years } \\
(n=31)\end{array}$ & $87 \% / 29 \%$ & $\begin{array}{l}92 \% \text { PFS at } 5 \text { years } \\
92 \% \text { OS at } 5 \text { years }\end{array}$ & $\begin{array}{l}\text { HTN 32\% } \\
\text { Pneumonia 10\% }\end{array}$ \\
\hline \multirow[t]{2}{*}{$\begin{array}{l}\text { Farooqui et al. }{ }^{[90,91]} \\
\text { NCT01500733 } \\
\text { (ibrutinib monotherapy) }\end{array}$} & $\begin{array}{l}\operatorname{Del}(17 \mathrm{p}) \\
\mathrm{TN}(n=35) \\
\mathrm{R} / \mathrm{R}(n=16)\end{array}$ & $98 \% / 29 \%$ & $\begin{array}{l}58 \% \text { PFS at } 5 \text { years } \\
76 \% \text { OS at } 5 \text { years }\end{array}$ & $\begin{array}{l}\text { Neutropenia 38\% } \\
\text { Thrombocytopenia 15\% }\end{array}$ \\
\hline & $\begin{array}{l}\text { Age }>65 \\
\mathrm{TN}(n=18) \\
\mathrm{R} / \mathrm{R}(n=17)\end{array}$ & $94 \% / 27 \%$ & $\begin{array}{l}81 \% \text { PFS at } 5 \text { years } \\
84 \% \text { OS at } 5 \text { years }\end{array}$ & \\
\hline $\begin{array}{l}\text { O'Brien et }{ }^{\prime}{ }^{[99]} \\
\text { RESONATE-17 } \\
\text { NCT01744691 } \\
\text { (ibrutinib monotherapy) }\end{array}$ & $\begin{array}{l}\mathrm{R} / \mathrm{R} \text { and } \operatorname{del}(17 \mathrm{p}) \\
(n=145)\end{array}$ & $83 \% / 10 \%$ & $\begin{array}{l}63 \% \text { PFS at } 24 \text { months } \\
75 \% \text { OS at } 24 \text { months }\end{array}$ & $\begin{array}{l}\text { Neutropenia } 18 \% \\
\text { Pneumonia } 13 \% \\
\text { HTN } 13 \%\end{array}$ \\
\hline $\begin{array}{l}\text { Burger et al. }{ }^{[100,101]} \\
\text { NCT01520519 } \\
\text { (ibrutinib-rituximab }^{\$} \text { ) }\end{array}$ & $\begin{array}{l}\text { High risk }{ }^{\&} \\
(n=40)\end{array}$ & $\begin{array}{l}95 \% / 23 \% \\
\text { PB uMRD in } 2 \\
\text { patients }\end{array}$ & $\begin{array}{l}\text { Median PFS } 45 \text { months } \\
73 \% \text { OS at } 36 \text { months }\end{array}$ & \\
\hline $\begin{array}{l}\text { Jaglowski et al. }{ }^{[102]} \\
\text { NCT01217749 } \\
\text { (Ibrutinib-ofatumumab }^{\#} \text { ) }\end{array}$ & $\begin{array}{l}\mathrm{R} / \mathrm{R} \text { and } \geq 2 \text { prior therapies } \\
(n=71)\end{array}$ & $83 \% / 1.5 \%$ & $\begin{array}{l}83 \% \text { PFS at } 12 \text { months } \\
89 \% \text { OS at } 12 \text { months }\end{array}$ & $\begin{array}{l}\text { Neutropenia } 24 \% \\
\text { Pneumonia } 17 \%\end{array}$ \\
\hline 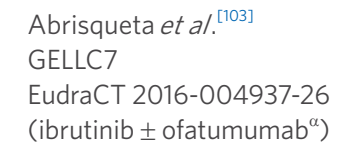 & $\begin{array}{l}\mathrm{TN}, \mathrm{CIRS}<6 \\
\mathrm{IBR}(n=84) \\
\mathrm{IBR}+\mathrm{OFA}(n=20)\end{array}$ & $\begin{array}{l}\text { IBR: } 94 \% / 5 \% \\
\text { +OFA: } 100 \% / 40 \% \\
\text { PB uMRD in } 1 \text { patient }\end{array}$ & $\begin{array}{l}98 \% \text { PFS at } 12 \text { months } \\
98 \% \text { OS at } 12 \text { months }\end{array}$ & Infections $17 \%$ \\
\hline \multicolumn{5}{|l|}{ Phase III } \\
\hline $\begin{array}{l}\text { Byrd et al. }{ }^{[23,95,96]} \\
\text { RESONATE }\end{array}$ & $\begin{array}{l}\mathrm{RR} \\
\operatorname{IBR}(n=195)\end{array}$ & $91 \% / 11 \%$ & $\begin{array}{l}\text { Median PFS } 44 \text { months } \\
83 \% \text { OS at } 18 \text { months }\end{array}$ & $\begin{array}{l}\text { Neutropenia } 20 \% \\
\text { Pneumonia } 10 \%\end{array}$ \\
\hline $\begin{array}{l}\text { NCT01578707 } \\
\text { (ibrutinib monotherapy } \\
\text { vs. ofatumumab^) }\end{array}$ & OFA $(n=196)$ & $4 \% / 0 \%$ & $\begin{array}{l}\text { Median PFS } 8 \text { months } \\
81 \% \text { at } 12 \text { months }\end{array}$ & Neutropenia 14\% \\
\hline $\begin{array}{l}\text { Burger et al. }{ }^{[97,98]} \\
\text { RESONATE-2 } \\
\text { NCT01722487 }\end{array}$ & $\begin{array}{l}T N \geq 65 \text { years without } \\
\operatorname{del}(17 p) \\
\operatorname{IBR}(n=136)\end{array}$ & $92 \% / 18 \%$ & $\begin{array}{l}89 \% \text { PFS at } 24 \text { months } \\
95 \% \text { OS at } 24 \text { moths }\end{array}$ & $\begin{array}{l}\text { Neutropenia } 12 \% \\
\text { Anemia } 7 \% \\
\text { HTN } 5 \%\end{array}$ \\
\hline $\begin{array}{l}\text { (ibrutinib monotherapy } \\
\text { vs. chlorambucil) }\end{array}$ & $\operatorname{CLB}(n=133)$ & $35 \% / 2 \%$ & $\begin{array}{l}\text { Median PFS } 15 \text { months } \\
84 \% \text { OS at } 24 \text { months }\end{array}$ & $\begin{array}{l}\text { Neutropenia } 18 \% \\
\text { Anemia } 8 \% \\
\text { Thrombocytopenia } 6 \%\end{array}$ \\
\hline \multirow{3}{*}{$\begin{array}{l}\text { Woyach et al. }{ }^{[19]} \\
\text { ALLIANCE } \\
\text { NCT01886872 } \\
\text { (Ibrutinib } \pm \text { rituximab }^{+} \\
\text {vs. Bendamustine- } \\
\text { rituximab }{ }^{+} \text {) }\end{array}$} & $\begin{array}{l}\mathrm{TN} \geq 65 \text { years } \\
\mathrm{IBR}(n=182)\end{array}$ & $\begin{array}{l}93 \% / 7 \% \\
\text { BM uMRD 1\% }\end{array}$ & $\begin{array}{l}87 \% \text { PFS at } 24 \text { months } \\
90 \% \text { OS at } 24 \text { months }\end{array}$ & $\begin{array}{l}\text { HTN } 29 \% \\
\text { Infection } 20 \% \\
\text { Neutropenia } 15 \% \\
\text { Thrombocytopenia 12\% } \\
\text { Anemia } 12 \%\end{array}$ \\
\hline & $\mathrm{IBR}+\mathrm{R}(n=183)$ & $\begin{array}{l}94 \% / 12 \% \\
\text { BM uMRD } 4 \%\end{array}$ & $\begin{array}{l}88 \% \text { PFS at } 24 \text { months } \\
94 \% \text { OS at } 24 \text { months }\end{array}$ & $\begin{array}{l}\text { HTN 33\% } \\
\text { Neutropenia 21\% } \\
\text { Infection 20\% } \\
\text { Thrombocytopenia 12\% }\end{array}$ \\
\hline & $\mathrm{BEN}+\mathrm{R}(n=183)$ & $\begin{array}{l}81 \% / 26 \% \\
\text { BM uMRD } 8 \%\end{array}$ & $\begin{array}{l}74 \% \text { PFS at } 24 \text { months } \\
95 \% \text { OS at } 24 \text { months }\end{array}$ & $\begin{array}{l}\text { Neutropenia } 40 \% \\
\text { HTN } 14 \% \\
\text { Anemia } 12 \% \\
\text { Infection } 15 \%\end{array}$ \\
\hline $\begin{array}{l}{\text { Moreno et } a l^{[18]}} \\
\text { iLLUMINATE } \\
\text { NCT02264574 } \\
\text { (ibrutinib-obinutuzumab }^{d}\end{array}$ & $\begin{array}{l}\mathrm{TN} \geq 65 \text { years or } \mathrm{CIRS}>6 \text { or } \\
\mathrm{CrCl}<70 \mathrm{~mL} / \mathrm{min} \text { or del }(17 \mathrm{p}) \\
\mathrm{IBR}+\mathrm{G}(n=113)\end{array}$ & $\begin{array}{l}91 \% / 41 \% \\
\text { PB uMRD 30\% } \\
\text { BM uMRD 20\% }\end{array}$ & $\begin{array}{l}79 \% \text { PFS at } 30 \text { months } \\
86 \% \text { OS at } 30 \text { months }\end{array}$ & $\begin{array}{l}\text { Neutropenia 37\% } \\
\text { Thrombocytopenia 19\% }\end{array}$ \\
\hline $\begin{array}{l}\text { vs. Chlorambucil- } \\
\text { obinutuzumab }^{d} \text { ) }\end{array}$ & $C L B+G(n=116)$ & $\begin{array}{l}81 \% / 16 \% \\
\text { PB uMRD 20\% } \\
\text { BM uMRD } 17 \%\end{array}$ & $\begin{array}{l}31 \% \text { PFS at } 30 \text { months } \\
85 \% \text { OS at } 30 \text { months }\end{array}$ & $\begin{array}{l}\text { Neutropenia } 46 \% \\
\text { Thrombocytopenia 10\% }\end{array}$ \\
\hline
\end{tabular}


Shanafelt et al. ${ }^{[17,104]}$ NCT02048813

E1912

(ibrutinib-rituximab

$v s$. Fludarabine-

cyclophosphamide-

rituximab)

\author{
$\mathrm{TN} \leq 70$ years without \\ del(17p) \\ $\mathrm{IBR}+\mathrm{R}(n=354)$ \\ $\operatorname{FCR}(n=175)$
}

$\begin{array}{ll}96 \% / 17 \% & 89 \% \text { at } 3 \text { years } \\ \text { PB uMRD } 8 \% & 99 \% \text { at } 3 \text { years } \\ & \\ 81 \% / 30 \% & 73 \% \text { at } 3 \text { years } \\ \text { PB uMRD 59\% } & 92 \% \text { at } 3 \text { years }\end{array}$

$96 \% / 17 \%$

PB UMRD 59\%
$92 \%$ at 3 years
Neutropenia 26\%

HTN 19\%

Neutropenia 45\%

Thrombocytopenia $15 \%$

Anemia 15\%

Infection 10\%

Febrile neutropenia 16\%

Ibrutinib (IBR) used as continuous therapy until progression, death, or other reason to withdraw in all trials. ${ }^{\circledR}$ del(17p) or TP53 mutated, relapsed del(11q) or relapse within three years of chemoimmunotherapy; ${ }^{\$}$ weekly rituximab $375 \mathrm{mg} / \mathrm{m}^{2}$ for Week $1-4$, then monthly rituximab up to six cycles; "ofatumumab administered as per prescribing manual (300 mg for Dose 1/2000 mg for Doses 2-12) with three groups, namely ibrutinib lead-in, ofatumumab lead-in and simultaneous treatment; ' ofatumumab administered intravenously 300 $\mathrm{mg}$ for Dose 1, $2000 \mathrm{mg}$ weekly for seven weeks, then $2000 \mathrm{mg}$ every four weeks up to 24 weeks total; ${ }^{+} 375 \mathrm{mg} / \mathrm{m}^{2}$ in Month 1, then 500 $\mathrm{mg} / \mathrm{m}^{2}$ each month to a total of six cycles; ${ }^{\alpha}$ seven cycles of ofatumumab added if no CR by Cycle 12 of ibrutinib (300 mg Day 1 and 1000 mg Day 8 of Cycle 13, 1000 mg Day 1 of Cycles 14-18); ${ }^{8} 100$ mg on Day 1, 900 mg on Day 2, 1000 mg on Day 8 and 1000 mg on Day 15 of Cycle 1, and subsequently $1000 \mathrm{mg}$ each month to a total of six cycles. ORR: overall response rate; CRR: complete response rate; PFS: progression free survival; OS: overall survival; R/R: relapsed and refractory; TN: treatment naïve; R: rituximab; CIRS: cumulative illness rating scale; $\mathrm{CrCl}$ : creatinine clearance; PB uMRD: peripheral blood measurable residual disease less than 10 ${ }^{-4}$; BM uMRD: bone marrow measurable residual disease less than $10^{-4}$; FCR: fludarabine, cyclophosphamide and rituximab; BEN: bendamustine; CLB: chlorambucil; G: obinutuzumab (100 mg on Day 1, 900 mg on Day 2, 1000 mg on Days 8 and 15, then 1000 mg on Day 1, 28 day cycles)

In younger patients whose disease lacked del(17p), ibrutinib-rituximab demonstrated improved PFS and OS over frontline FCR despite inferior attainment of complete and uMRD remissions, although deepening of response is expected with extended follow up ${ }^{[17]}$. At a median follow up of 45 months, no PFS benefit has been observed in subgroup analysis of patients with IGHV mutated disease ${ }^{[104]}$, in whom FCR can achieve extended remissions ${ }^{[2]}$. The choice of frontline therapy in this subgroup is likely to remain controversial until longer-term follow up data are available. Overall, Phase III data now support the use of ibrutinib-based regimens over CIT for the majority of patients with CLL, with particular benefit for elderly patients not previously eligible for the most effective CIT regimens and patients whose disease bears TP53 abnormalities in whom durable responses now commonly seen with ibrutinib were previously rare.

The benefit of combining ibrutinib with anti-CD20 monoclonal antibodies is unclear. Although the Phase III trials comparing ibrutinib-based therapy to chlorambucil-obinutuzumab and FCR both utilized concomitant rituximab, the ALLIANCE trial showed no PFS benefit with rituximab combination compared to ibrutinib monotherapy ${ }^{[19]}$. In addition, a recent randomized trial comparing ibrutinib-rituximab to ibrutinib monotherapy for patients with relapsed or TP53 aberrant CLL found earlier peripheral lymphocyte count normalisation, $\mathrm{CR}$ and more frequent attainment of BM uMRD status with combination treatment; however, this did not translate to an improvement in PFS or OS over a median follow up of three years ${ }^{[105]}$. Preclinical data suggest that ibrutinib may impair natural killer cell and macrophage function and thus antagonise the antibody dependent cellular cytotoxicity (ADCC) of rituximab ${ }^{[106-108]}$; it may also downregulate CD20 expression on CLL cells through disruption of microenvironment signals ${ }^{[109]}$. This interference may be largely driven by inhibition of non-BTK kinases such as interleukin-2 inducible tyrosine kinase (ITK), and in vitro experiments suggest more selective BTK inhibitors may spare anti-CD20 $\mathrm{ADCC}^{[110]}$. Contrary to this hypothesis, acalabrutinib combined with obinutuzumab achieved a low CRR of $8 \%$ in a Phase I/II study in R/R CLL ${ }^{[111]}$, compared to a CRR of $3 \%$ with acalabrutinib monotherapy ${ }^{[112]}$, questioning the yield of combination. Preliminary data from the Phase III ELEVATE TN study did not demonstrate superior PFS with acalabrutinib-obinutuzumab compared to acalabrutinib alone (30-month PFS $90 \%$ vs. $82 \%)$, although CRs appear more frequent $(13 \% v s .<1 \%)$ and longer-term follow up is required $^{[113]}$. The ostensibly increased speed and depth of response observed with ibrutinib-obinutuzumab in the iLLUMINATE trial suggests an enhanced clearance of malignant cells with combination therapy ${ }^{[18]}$, and the enhanced cytotoxicity of obinutuzumab may be less compromised by ibrutinib co-administration than rituximab ${ }^{[114-118]}$. In two similarly designed Phase II trials combining ibrutinib with obinutuzumab or ofatumumab after bendamustine debulking treatment, patients in the obinutuzumab trial achieved a 
higher rate of $\mathrm{PB}$ UMRD response compared to the ofatumumab group ( $48 \%$ vs. $14 \%$ ), further endorsing the possibility that obinutuzumab may be the superior partner to ibrutinib over earlier generation antiCD20 monoclonals ${ }^{[119,120]}$. Ultimately, longer-term follow up of randomized studies will be required to establish the role of anti-CD20 monoclonal combination, which may be influenced by the kinome of the BTK inhibitor or the properties of the monoclonal antibody. Whether the improved PFS and OS over FCR observed in younger, TN patients in the E1912 trial is dependent on concomitant rituximab is unclear, as is the benefit of ibrutinib-obinutuzumab combination over ibrutinib monotherapy in elderly and comorbid patients.

Immune reconstitution may also represent an advantage of ibrutinib therapy. Sun et al. ${ }^{[121]}$ observed increased serum IgA levels in patients with CLL receiving ibrutinib, with fewer infections in patients with greater IgA improvements. Ibrutinib can increase CD4+ and CD8+ numbers, reduce CLL mediated immunosuppression ${ }^{[122]}$ and may enhance Th1 subtype activity and anti-parasite immunity through ITK inhibition ${ }^{[123]}$. Preliminary data also suggest ibrutinib may enhance the proliferative capacity and efficacy of CAR T cells, possibly through reduced expression of programmed death protein 1 (PD1) on T cells ${ }^{[124-126]}$, and expand host CD8+ subpopulations with cytotoxicity against CLL cells ${ }^{[127]}$. In contrast, however, ibrutinib has also been shown to compromise BTK-dependent macrophage activation in response to Aspergillus fumigatus infection in mouse models ${ }^{[128]}$. Initial case reports suggested an association between ibrutinib therapy and invasive fungal infections ${ }^{[129-132]}$, including a high rate of invasive Aspergillosis in patients receiving the agent for central nervous system lymphoma ${ }^{[133,134]}$. A retrospective review of 33 invasive fungal infections in patients receiving ibrutinib at French centres identified Aspergillus species as the most common organisms (27/33), with cerebral involvement in $40 \%$ of cases ${ }^{[135]}$. In an analysis of 459 patients receiving ibrutinib for lymphoma at the Memorial Sloan Kettering Cancer Centre, 16 (4.2\%) instances of invasive fungal infections were identified, with proven or probable invasive aspergillosis accounting for $50 \%$ of cases. The remainder were Pneumocystis jiroveci pneumonia (PJP) $(n=4)$, pulmonary Cryptococcus $(n=3)$ and C. albicans fungemia $(n=1)^{[136]}$. In another review of 566 patients receiving ibrutinib for lymphoma, opportunistic infections occurred in $2.3 \%$ of patients at six months and $4.7 \%$ of patients at five years, predominantly due to fungal (mainly Aspergillus) infections with no cases of PJP. Opportunistic infections were not observed in patients receiving ibrutinib as frontline therapy and were associated with higher number of previous treatments, suggesting that the cumulative immunosuppressive effects of prior therapies may contribute to the risk ${ }^{[137]}$. Overall, opportunistic infections appear to be an uncommon but serious adverse effect of ibrutinib therapy. The immune effects of ibrutinib are clearly multifaceted and mediated by on target and off target kinase inhibition. The immunological impact of BTK inhibitor therapy warrants further study, particularly in more selective BTK inhibitors for which the longerterm immunological effects are unknown ${ }^{[138,139]}$.

\section{Pitfalls}

Although ibrutinib achieves improved disease control for the majority of patients, the rare attainment of deep responses (especially uMRD) demands continuous use, leading to several emerging concerns. Discontinuation of therapy due to cumulative toxicity is common, especially in the elderly and patients outside of clinical trials. Despite significant activity against disease with del(17p)/TP53 mutations and complex karyotype, extended follow up has identified inferior PFS in these patients in the longer term. For patients who are able to tolerate long-term therapy, the emergence of resistant disease is common if not inevitable, commonly bearing BTK point mutations at Cys481 that disable irreversible inhibition by ibrutinib.

With continuous use, treatment limiting toxicities with ibrutinib are commonly encountered. In a pooled analysis of 616 patients treated with ibrutinib in clinical trials and routine practice, $41 \%$ of patients discontinued therapy at a median of seven months. Toxicity was the most common reason for cessation, 
attributable to $63 \%$ of treatment terminations in TN patients and $50 \%$ of patients with $\mathrm{R} / \mathrm{R}$ disease. By comparison, progressive disease was a less common reason for cessation, accounting for $16 \%$ of TN and $21 \%$ of previously treated patients ${ }^{[93]}$. Similar data have been observed in another recent description of 205 patients receiving ibrutinib outside of clinical trials ( $42 \%$ discontinuation due to adverse effects and median time to discontinuation of nine months $)^{[140]}$. Among young fit TN patients treated with ibrutinib-rituximab in the E1912 trial, the rate of cessation due to adverse effects or complications was lower (14\% at a median follow up of 45 months), but was nevertheless the most common reason for cessation, accounting for $51 \%$ of terminations (compared to $24 \%$ due to progressive disease). Higher cumulative illness rating scale scores were associated with a higher rate of treatment cessation for reasons other than progressive disease or death ${ }^{[104]}$. These observations indicate that the potential durable disease control offered by ibrutinib therapy is often compromised by treatment limiting toxicity. The most common adverse effects accounting for treatment termination were arthralgia, atrial fibrillation, rash, infection, bleeding and diarrhea ${ }^{[93]}$, with older, heavily pre-treated and comorbid patients more likely to discontinue due to toxicity ${ }^{[3,104,141]}$. In the $\mathrm{TN}$ setting, $41 \%$ of toxicity-driven cessation was due to arthralgia, but published data on the pathophysiology and management of this phenomenon are lacking ${ }^{[33]}$. Bleeding affects up to half of all patients treated with ibrutinib, although this is typically minor, with a cumulative major haemorrhage rate of $9 \%$ at five-year follow up ${ }^{[14]}$. The ibrutinib bleeding diathesis is likely mediated through on target and off target kinase inhibition, supported by in vitro data and the observation that congenital BTK deficiency in $\mathrm{X}$-linked agammaglobulinemia is not associated with increased bleeding ${ }^{[142-144]}$. Atrial fibrillation occurs in approximately $10 \%$ of patients over 36 months ${ }^{[145]}$, and may be mediated by decreased PI3K-AKT signalling in cardiomyocytes due to BTK and Tec protein kinase inhibition ${ }^{[146]}$. More concerningly, ibrutinib appears to increase the risk of sudden cardiac death and ventricular arrhythmias. Pooled analysis of patients receiving ibrutinib have estimated an incidence of 617-788 events per 100,000 person-years, compared to the expected rate among healthy 65 year olds of $200-400$ events per 100,000 person-years ${ }^{[147,148]}$. Seven instances of unexplained sudden death (4\%) occurred in the ibrutinib monotherapy arm of the ALLIANCE trial compared to two cases in the BR cohort (1\%), potentially contributing to the failure to recapitulate the survival benefit over CIT seen in younger patients ${ }^{[19]}$. Similarly, seven cases of ventricular arrhythmia or sudden death occurred in the ibrutinib arm of the HELIOS trial (2\%) compared to no events in the placebo arm ${ }^{[149]}$. Estimates for the median time to first ventricular event from ibrutinib initiation vary from 2 to 16 months, with cases reported as early as five days on therapy and beyond four years ${ }^{[147,148]}$. Although these events are rare, the phenomenon is concerning, especially considering the increasing options and life expectancy for patients with CLL. Overall, toxicity significantly compromises the deliverability of continuous ibrutinib therapy, calling for the development of less toxic, more selective BTK inhibitors or the use of combination therapy to achieve deep remission that facilitates drug cessation.

Acalabrutinib (ACP-196) is a second-generation BTK inhibitor without irreversible inhibitory action against epidermal growth factor receptor, TEC and ITK, as seen with ibrutinib. In initial data from a Phase I/II study in patients with R/R CLL, acalabrutinib maintained a high ORR of 95\% with no atrial fibrillation after 14-month follow up, although arthralgia and petechial bleeding both occurred in $16 \%$ of patients ${ }^{[138]}$, and one Grade III bleeding event (epistaxis) occurred with extended follow up ${ }^{[112]}$. Similarly high ORR has been observed TN patients, with Grade III/IV atrial fibrillation, bleeding and hypertension occurring in $2 \%$, $3 \%$ and $7 \%$ of patients, respectively, at median time on study of 42 months ${ }^{[150,151]}$. Among 60 patients intolerant of ibrutinib with progressive CLL treated with acalabrutinib, $67 \%$ of patients remained on drug at a median follow up of 19 months, with $13 \%$ ceasing due to progression and $10 \%$ due to adverse effects. Atrial fibrillation and major haemorrhage occurred in three and two patients, respectively ${ }^{[152]}$. Overall, these preliminary data suggest that acalabrutinib is active against CLL, and may reduce, but not preclude, the toxicities seen with ibrutinib.

Tirabrutinib (ONO/GS-4059), a similarly selective BTK inhibitor, achieved objective responses in $96 \%$ of patients with R/R CLL in a Phase I clinical trial, with no atrial fibrillation observed after a median follow 
up of three years, although one Grade III haematoma has been reported and low grade arthralgias and bruising are common ${ }^{[153,154]}$. A third selective BTK inhibitor, zanubrutinib (BGB-3111), has also shown preserved efficacy in CLL (ORR/CRR 97\%/14\%), with infrequent major bleeding and atrial fibrillation (2\%-3\% of patients after a median follow up of 27 months) and more patients ceasing due to progressive disease than adverse effects $(11 \% \text { vs. } 3 \%)^{[139,155]}$. Together with high early response rates, the relative rarity of major bleeding and arrhythmias with these agents is particularly encouraging, and support the currently active trials which interrogate whether selective BTK inhibition can preserve therapeutic efficacy while minimising toxicity.

Another potential strategy to manage ibrutinib adverse effects is dose reduction. Several retrospective analyses of patients treated outside of clinical trials found no evidence of inferior disease control among patients who required dose reductions ${ }^{[156-158]}$. Phase I data suggest that a progressive reduction from $420 \mathrm{mg} /$ day in Cycle 1 to $140 \mathrm{mg} /$ day by Cycle 3 does not reduce biochemical BTK occupancy ${ }^{[159]}$. Although prospective clinical data are required to determine the impact of dose reduction on disease control and adverse effects, current data suggest that a trial of dose reduction in response to adverse effects may not necessarily compromise treatment efficacy.

Unfortunately, for patients who are able to tolerate long-term ibrutinib, the development of resistant disease is common, if not inevitable, among patients with previously treated or TP53 aberrant disease $\mathrm{e}^{[14,90,96]}$. Primary resistance to ibrutinib is unusual in CLL, although extensive prior treatment and bulky disease are associated with inferior $\mathrm{CR}$ attainment on multivariate analysis ${ }^{[160]}$. In a cohort of 70 patients treated with ibrutinib, higher levels of surface IgM were associated with earlier time to progression on univariate analysis, possibly due to IgM mediated preservation ERK signalling despite BTK inhibition ${ }^{[161]}$. In a retrospective pooled analysis for four Phase II and III trials, the pre-treatment risk factors of TP53 mutations, advanced Rai stage, elevated beta-2-microglobulin and prior treatment were associated earlier development of resistant disease ${ }^{[162]}$. At five-year follow up of early phase trials, del(17p) and greater number of prior therapies were associated with inferior PFS and OS on multivariate analysis ${ }^{[14]}$. Concordantly, extended follow up of the RESONATE trial suggested that patients whose disease harboured del(17p) and/or TP53 mutations had an inferior PFS compared to patients whose disease had neither abnormality ${ }^{[95,96]}$. In a retrospective analysis of 616 patients, predominantly with $\mathrm{R} / \mathrm{R}$ disease, complex karyotype, but not del(17p), was associated with inferior $\mathrm{PFS}^{\left[{ }^{93}\right]}$, supporting similar observations that complex karyotype is the more potent adverse prognostic indicator ${ }^{[94,141,163,164]}$. Overall, these data suggest that patients whose disease contains TP53 abnormalities have an inferior duration of response to ibrutinib, although this may be driven predominantly by the enrichment for complex karyotype within this group. Similar to observations in venetoclax-treated patients, TP53 abnormalities appear to facilitate acquisition of secondary resistance mechanisms and subsequent progressive disease without compromising initial responses to targeted therapy.

The most well described mechanisms of secondary resistance are acquisition of mutations in the BTK gene at the Cys481 residue or, less commonly, activating mutations in phospholipase C gamma 2 (PLCG2). These mutations were first described in six patients with progressive CLL, all of whom had del(11q), del(17p) or complex karyotype at ibrutinib commencement. The Cys481Ser mutation at the ibrutinib binding site degrades BTK inhibition from irreversible to reversible, restoring downstream ERK and AKT signalling. The gain-of-function PLCG2 mutations enable BTK-independent signalling downstream of the BCR, similarly reactivating ERK and AKT activity. Many mutations lie within the Src homology domain 2 (SH2) autoregulatory domain of PLCG2, accounting for the constitutive phosphorylation and activation conferred $^{[27]}$; however, the mechanism of other described mutations outside the SH2 domain is less clear ${ }^{[165]}$. Variant substitutions at the Cys481 residue, alternative BTK mutations and diverse PLCG2 mutations have now been identified ${ }^{[31,166-170]}$, altogether occurring in $85 \%$ of patients relapsing on ibrutinib in the largest 
published dataset ${ }^{[141]}$, comparable to other groups ${ }^{[169,171]}$. BTK mutations also appear to be common among patients relapsing on acalabrutinib ${ }^{[169,172]}$. An alternative BTK mutation Leu528Trp has recently been shown to co-occur with Cys481 mutations in patients whose disease progresses on zanubrutinib, although this mutation appears to compromise the enzymatic activity of $\mathrm{BTK}^{[173]}$. As seen with point mutations conferring resistance to venetoclax, these mutations have not been identified in pre-treatment samples ${ }^{[174]}$. Mutations have been detected up to 18 months prior to clinical progression, with a median time from detection to clinical relapse of nine months ${ }^{[141]}$. Although these mutations are clearly relevant to resistance, $15 \%-20 \%$ of patients progressing on ibrutinib likely harbour an alternative mechanism. Furthermore, variant allele frequency of $B T K$ mutations are low $(<10 \%)$ in some disease at progression, which may be due compartmental nodal relapse or, as suspected with venetoclax resistance, polyclonal progression utilizing multiple resistance mechanisms ${ }^{[141]}$. Comparison of gene sequencing results pre- and post-BTK inhibitor therapy identified new mutations in TP53, SF3B1, NOTCH1, POT1 and CARD11 in seven patients who progressed on ibrutinib without BTK/PLCG2 mutations ${ }^{[169]}$. A recent analysis of 180 patients treated with single agent ibrutinib identified an association between $\mathrm{NOTCH} 1$ mutations and inferior nodal response, PFS and OS, supporting its putative role in ibrutinib resistance ${ }^{[62]}$. Infrequent co-acquisition of these new mutations with BTK/PLCG2 mutations indicates potentially independent mechanisms. Moreover, disease harbouring BTK/PLGC2 mutations had a significantly longer time to clinical progression compared to alternative mutants, which may imply a proliferative disadvantage in the BTK/PLCG2 mutated clone ${ }^{[169]}$. In patients without these mutations, expansion of sub-clones harbouring $\operatorname{del}(8 \mathrm{p})$ has been reported as an alternative mechanism of resistance, potentially through decreased expression of the tumour necrosis factor alpha apoptosis-inducing ligand (TRAIL) receptor and failure of TRAIL-induced apoptosis ${ }^{[167]}$.

Potential therapeutic strategies for BTK/PLCG2 mutated CLL include inhibition of BCL2, disruption of alternate BCR pathway kinases and the use of novel BTK inhibitors which do not rely on the Cys481 residue for binding. In patients with progressive CLL after ibrutinib treatment, venetoclax achieved an ORR $65 \%$, CRR of $9 \%$ and PB uMRD status in $26 \%$, with an associated median PFS of 25 months. Among 17 patients with BTK/PLCG2 mutations, venetoclax achieved a response in 12 (71\%) patients (11 PR; 1 CR), with a falling BTK Cys481Ser allelic frequency in all cases assessed and no significant difference in PFS between patients with and without mutations ${ }^{[46]}$. Suppression of the BTK/PLCG2 variant allelic burden by venetoclax has also been reported by another group ${ }^{[169]}$, arguing that such clones retain BCL2 dependence. In a retrospective analysis, idelalisib achieved an ORR of $46 \%$ (CRR 0\%) and a median PFS of nine months in patients who discontinued ibrutinib ${ }^{[175]}$, suggesting venetoclax may be the more effective agent in this setting. Preliminary data from the Phase II COSMOS trial demonstrated frequent responses in heavily pretreated patients whose disease had progressed after BTK inhibitor therapy using the anti-CD19 monoclonal antibody tafasitamab in combination with idelalisib or venetoclax, achieving PB uMRD status in 1/11 (9\%) and $6 / 13(46 \%)$ patients, respectively ${ }^{[176]}$. Duvelisib, an inhibitor of PI3K isoforms d and g, demonstrated poor response rates in R/R CLL previously treated with ibrutinib in a Phase I study ${ }^{[177]}$. Despite the biological rationale of inhibiting kinases upstream of BTK and PLCG2, the spleen tyrosine kinase (SYK) inhibitor entospletinib (GS-9973) achieved an ORR of only $24 \%$ and a median PFS of 3-8 months in ibrutinib exposed R/R CLL ${ }^{[181]}$. Vecabrutinib (SNS-062), a reversible BTK inhibitor independent of the Cys481 residue, has in vitro cytotoxicity against BTK Cys481-mutated cell lines ${ }^{[179,180]}$ and preliminary safety data in patients with CLL ${ }^{[173]}$. Similarly, LOXO-305 is an oral bioavailable selective non-covalent BTK inhibitor that can interrupt Cys481 mutated BTK, with responses in all CLL patients treated in a Phase I study, including one patient with disease harbouring the Cys481Ser mutation ${ }^{[182-184]}$. Several other BTK inhibitors are in development and may ultimately prove efficacious against BTK mutated disease ${ }^{[185-189]}$. Currently, venetoclax appears to be the best supported therapy for patients progressing with CLL on ibrutinib. Given that BTK and PLCG2 mutations are detected after a median of nine months on ibrutinib monotherapy ${ }^{[141]}$, it remains unknown if time-limited venetoclax-ibrutinib combination will restrain their emergence, or obviate the continuous ibrutinib exposure that drives their selection. 


\section{Summary: ibrutinib}

Phase III trial data endorse ibrutinib as an effective and durable treatment for most of the common clinical scenarios within CLL; however, deep remissions are rare and continuous therapy is required. We recommend ibrutinib-based therapy as a frontline for most patients, especially those with TP53 abnormalities. Fit, young patients with TP53 wildtype, IGHV mutated disease should be counselled on the merits of FCR or ibrutinib-rituximab therapy. For patients with established cardiovascular comorbidity, we favour venetoclax-based therapy if available. Chlorambucil-obinutuzumab is a reasonable treatment for patients with comorbidities if the availability of novel agents is limited. We recommend venetoclaxrituximab for the treatment of ibrutinib resistant CLL. Inevitable resistance and treatment-limiting toxicity currently complicate continuous ibrutinib therapy, and we hope these will be addressed by longer-term follow up of more targeted BTK inhibitors and time-limited novel agent combination therapy.

\section{IDELALISIB}

\section{Mechanism}

Idelalisib (GS-1101/CAL-101) is a selective inhibitor of the p110d isoform of PI3K, an enzyme downstream of the BCR responsible for transduction of pro-survival signals in CLL ${ }^{[190]}$. The $\mathrm{d}$ isoform of PI3K is highly expressed in lymphoid cells, and inhibition of this enzyme interrupts downstream AKT signalling ${ }^{[190,191]}$ and microenvironment protection from apoptosis ${ }^{[66,192]}$. Based on Phase III trial data, idelalisib is currently FDA approved for treatment of R/R CLL in combination with rituximab ${ }^{[16]}$.

\section{Promises}

Despite only modest efficacy in the Phase I/II monotherapy trials ${ }^{[191,193]}$, idelalisib combined with rituximab or ofatumumab achieved an ORR/CRR of $83 \% / 5 \%$ in patients with R/R CLL, with a median PFS of 24 months ${ }^{[194,195]}$. In a Phase III trial comparing rituximab with and without idelalisib for patients with R/ R CLL unable to receive CIT, idelalisib-rituximab combination demonstrated an ORR of $81 \%$ (no CRs) and superior PFS and OS (66\% vs. 13\% PFS at 12 months; $92 \%$ OS vs. $80 \%$ OS at 12 months). As seen in other targeted therapies, the PFS benefit was maintained in patients whose disease harboured del(17p)/ TP53 mutations or was IGHV unmutated ${ }^{[16]}$. The published clinical trial data for idelalisib in CLL are summarised in Table 3.

\section{Pitfalls}

Although idelalisib represents another targeted therapy with efficacy in traditional high-risk disease, the depth and duration of response seen in Phase III clinic trials is modest compared with outcomes in comparable trials with ibrutinib and venetoclax ${ }^{[23,44,95,96]}$. In a retrospective analysis, patients receiving ibrutinib as first BCR pathway inhibitor in either the frontline or R/R setting had superior PFS compared to patients receiving idelalisib as initial therapy ${ }^{[175]}$. In the ASCEND trial, patients with R/R CLL were randomised to receive acalabrutinib monotherapy or investigator's choice of idelalisib-rituximab or bendamustine-rituximab, with the majority of investigators selecting idelalisib-rituximab (199 patients vs. 36 patients bendamustine-rituximab). Acalabrutinib treatment was associated with a significantly prolonged PFS (12-month PFS $88 \%$ vs. 68\%) and superior tolerability compared to investigator's choice ${ }^{[196]}$, strengthening the argument for BTK inhibitors over PI3K inhibitors. Compounding this apparently inferior efficacy are concerns regarding deliverability, with $94 \%$ of patients discontinuing therapy at a median of six months in a large retrospective analysis, more commonly due to toxicity than progressive disease ( $45 \%$ vs. $28 \%$ of discontinuations, respectively). Immune phenomena, particularly pneumonitis, colitis, rash and transaminitis, were the most common reasons for cessation ${ }^{[175]}$. Although poorly understood, these events may be related to inhibition of PI3K p100 $\delta$ in regulatory T cells, leading to enhanced CD $8+\mathrm{T}$ cell activity $^{[197,198]}$ and Th17 phenotype ${ }^{[199]}$. In one young TN cohort treated with idelalisib and ofatumumab, Grade $\geq$ III immune mediated hepatotoxicity occurred in 52\% of patients, and 55\% of patients discontinued 
Table 3. Phase I/II and III trials of idelalisib \pm anti-CD20 monoclonal antibodies

\begin{tabular}{|c|c|c|c|c|}
\hline Study & Cohort & ORR/CRR MRD & PFS/OS & III/IV toxicity (> 10\%) \\
\hline \multicolumn{5}{|l|}{ Phase I/II } \\
\hline $\begin{array}{l}\text { Brown et al. }{ }^{[191]} \\
\text { NCT00710528 } \\
\text { NCT01090414 } \\
\text { (idelalisib monotherapy) }\end{array}$ & $\begin{array}{l}\mathrm{R} / \mathrm{R} \text { CLL } \\
(n=54)\end{array}$ & $72 \% / 0 \%$ & $\begin{array}{l}\text { Median PFS } 16 \text { months } \\
75 \% \text { OS at } 3 \text { years }\end{array}$ & $\begin{array}{l}\text { Neutropenia } 43 \% \\
\text { Pneumonia 20\% } \\
\text { Neutropenic fever } 11 \%\end{array}$ \\
\hline $\begin{array}{l}\text { Furman et } a{ }^{\left[.^{[194,195]}\right.} \\
\text { (idelalisib }+ \text { rituximab }{ }^{\%} \text { or } \\
\text { ofatumumab }{ }^{\wedge} \text { ) }\end{array}$ & $\begin{array}{l}\mathrm{R} / \mathrm{R} C L \mathrm{~L} \\
(n=40)\end{array}$ & $83 \% / 5 \%$ & $\begin{array}{l}\text { Median PFS } 24 \text { months } \\
80 \% \text { OS at } 24 \text { months }\end{array}$ & $\begin{array}{l}\text { Diarrhea/colitis 23\% } \\
\text { Pneumonia } 18 \%\end{array}$ \\
\hline $\begin{array}{l}\text { O'Brien et } a l_{.}^{[200]} \\
\text { NCT01203930 } \\
\text { (idelalisib-rituximab\%) }\end{array}$ & $\begin{array}{l}\mathrm{TN} \geq 65 \text { years } \\
(n=64)\end{array}$ & $97 \% / 19 \%$ & $\begin{array}{l}\text { PFS } 83 \% \text { at } 3 \text { years } \\
\text { OS } 90 \% \text { at } 3 \text { years }\end{array}$ & $\begin{array}{l}\text { Diarrhea/colitis } 42 \% \\
\text { Neutropenia } 28 \% \\
\text { ALT/AST elevation 23\% } \\
\text { Pneumonia } 19 \%\end{array}$ \\
\hline $\begin{array}{l}\text { Zelenetz et al. }{ }^{[193]} \\
\text { (idelalisib monotherapy) }\end{array}$ & $\begin{array}{l}\mathrm{TN} \geq 65 \text { years } \\
(n=37)\end{array}$ & $81 \% / 0 \%$ & NA & Neutropenia $20 \%$ \\
\hline $\begin{array}{l}\text { Lampson et al. }{ }^{[201]} \\
\text { NCT02135133 } \\
\text { (idelalisib-ofatumumab^) }\end{array}$ & $\begin{array}{l}\mathrm{TN} \\
(n=27)\end{array}$ & $89 \% / 4 \%$ & $\begin{array}{l}\text { Median PFS } 23 \text { months } \\
\text { OS } 88 \% \text { at } 3 \text { years }\end{array}$ & $\begin{array}{l}\text { ALT/AST elevation 52\% } \\
\text { Neutropenia 33\% } \\
\text { Colitis/diarrhea 15\% }\end{array}$ \\
\hline \multicolumn{5}{|l|}{ Phase III } \\
\hline \multirow[t]{3}{*}{$\begin{array}{l}\text { Coutre et al. }{ }^{[202]} \\
\text { NCT01088048 } \\
\text { (idelalisib } \pm \text { rituximab }^{\%} \pm \\
\text { bendamustine) }\end{array}$} & $\begin{array}{l}\mathrm{R} / \mathrm{R} C L \mathrm{~L} \\
\mathrm{IDEL}+\mathrm{R}(n=19)\end{array}$ & $90 \% / 0 \%$ & Median PFS 37 months & $\begin{array}{l}\text { Neutropenia } 26 \% \\
\text { Pneumonia } 21 \% \\
\text { Diarrhea } 16 \% \\
\text { Febrile neutropenia } 16 \%\end{array}$ \\
\hline & IDEL + BEN $(n=18)$ & $78 \% / 6 \%$ & Median PFS 19 months & $\begin{array}{l}\text { Neutropenia } 67 \% \\
\text { Thrombocytopenia 22\% } \\
\text { Anemia } 28 \% \\
\text { AST/ALT elevation 22\% } \\
\text { Pneumonia } 22 \% \\
\text { Sepsis } 22 \% \\
\text { Febrile neutropenia } 17 \%\end{array}$ \\
\hline & IDEL + BEN + R $(n=15)$ & $88 \% / 13 \%$ & Median PFS 23 months & $\begin{array}{l}\text { Neutropenia 60\% } \\
\text { Anemia 13\% } \\
\text { Diarrhea 13\% } \\
\text { Pneumonia 13\% } \\
\text { Rash 13\% }\end{array}$ \\
\hline \multirow[t]{2}{*}{$\begin{array}{l}\text { Furman et al. }{ }^{[16,203]} \\
\text { NCT01539512 } \\
{\text { (idelalisib-rituximab }{ }^{\#} \text { vs. }}_{\text {rituximab monotherapy }} \text { ) }\end{array}$} & $\begin{array}{l}\text { R/R CLL with: } \\
\text { myelosuppression, } \mathrm{CrCl}<60 \\
\mathrm{~mL} / \mathrm{min} \text { or } \mathrm{CIRS}>6 \\
\mathrm{IDEL}+\mathrm{R}(n=110)\end{array}$ & $81 \% / 0 \%$ & $\begin{array}{l}66 \% \text { PFS at } 12 \text { months } \\
92 \% \text { OS at } 12 \text { months }\end{array}$ & $\begin{array}{l}\text { Neutropenia 34\% } \\
\text { Thrombocytopenia 10\% }\end{array}$ \\
\hline & $\mathrm{R}(n=110)$ & $13 \% / 0 \%$ & $\begin{array}{l}13 \% \text { PFS at } 12 \text { months } \\
80 \% \text { OS at } 12 \text { months }\end{array}$ & $\begin{array}{l}\text { Neutropenia } 22 \% \\
\text { Thrombocytopenia } 16 \% \\
\text { Anemia } 14 \%\end{array}$ \\
\hline \multirow{2}{*}{$\begin{array}{l}\text { Jones et al. }{ }^{[204,205]} \\
\text { NCT01659021 } \\
\text { (idelalisib-ofatumumab^vs. } \\
\text { ofatumumab monotherapy }{ }^{\star} \text { ) }\end{array}$} & $\begin{array}{l}\text { R/R CLL } \\
\text { IDEL + OFA }(n=174)\end{array}$ & $75 \% / 0 \%$ & $\begin{array}{l}\text { Median PFS } 16 \text { months } \\
\text { Median OS NR }\end{array}$ & $\begin{array}{l}\text { Neutropenia 34\% } \\
\text { Diarrhea 23\% } \\
\text { Pneumonia 20\% }\end{array}$ \\
\hline & OFA $(n=87)$ & $18 \% / 0 \%$ & $\begin{array}{l}\text { Median PFS } 8 \text { months } \\
\text { Median OS NR }\end{array}$ & Neutropenia 16\% \\
\hline
\end{tabular}

Idelalisib (IDEL) used as continuous therapy until progression, death, or other reason to withdraw in all trials. ${ }^{\%} 375 \mathrm{mg} / \mathrm{m}^{2}$ weekly for 6-8 weeks; ${ }^{\#} 375 \mathrm{mg} / \mathrm{m}^{2}$ for first dose, $500 \mathrm{mg} / \mathrm{m}^{2}$ every two weeks for four doses, then $500 \mathrm{mg} / \mathrm{m}^{2}$ every four weeks for three doses (total eight doses). OFA^: ofatumumab intravenously $300 \mathrm{mg}$ Week 1, $1000 \mathrm{mg}$ Weeks 2-7, $1000 \mathrm{mg}$ Q4 weekly $\times$ 4; OFA*: ofatumumab intravenously 300 mg Week 1, 2000 mg Weeks 2-7, 2000 mg Q4 weekly $\times$ 4. ORR: overall response rate; CRR: complete response rate; PFS: progression free survival; OS: overall survival; R/R: relapsed and refractory; TN: treatment naïve; R: rituximab; BEN: bendamustine; CIRS: cumulative illness rating scale; $\mathrm{CrCl}$ : creatinine clearance; PB uMRD: peripheral blood measurable residual disease less than $10^{-4}$; BM UMRD: bone marrow measurable residual disease less than $10^{-4}$

therapy at a median of eight months due to toxicity ${ }^{[201,206]}$. In contrast, a pooled analysis of 760 patients observed Grade $\geq$ III transaminitis in only $13 \%-16 \%$ of subjects ${ }^{[207]}$, suggesting these adverse effects may be more common in younger patients treated in the frontline. Two deaths due to immune mediated colitis and hepatitis led to termination of a Phase I trial of lenalidomide, idelalisib and rituximab ${ }^{[208]}$, and frequent severe pneumonitis prohibited the combination of idelalisib with entospletinib ${ }^{[209]}$. Given these observations regarding modest efficacy and treatment limiting toxicity, durable disease control with idelalisib is less common than with ibrutinib or venetoclax. In contrast to venetoclax and ibrutinib, Phase 
III trials supporting idelalisib over other established treatments have not emerged, confining its use to the R/R setting.

Although progressive disease on idelalisib does occur, the mechanisms for resistance are poorly understood. Point mutations at the active binding site, as seen in ibrutinib and venetoclax resistance, have not been identified on whole exome sequencing of patients relapsing on idelalisib ${ }^{[210]}$. In a mouse model of idelalisib resistance, resistant CLL cells exhibited increased mitogen-actived protein kinase (MAPK) signalling through enhanced expression of insulin-like growth factor 1 receptor (IGF1R), which could be abrogated using a small molecule inhibitor, lisitinib. Increased IGF1R expression was identified on CLL cells from one patient with progression on idelalisib, with restoration of idelalisib sensitivity when treated with lisitinib in vitro ${ }^{[210]}$. Whole exome sequencing experiments in this mouse model also identified frequent mutations relevant to integrin and extracellular matrix signalling ${ }^{[211]}$. Although promising, these preclinical observations are yet to be recapitulated in a larger analyses of patient samples.

Duvelisib (IPI-145) is a dual inhibitor of the $\mathrm{d}$ and $\mathrm{g}$ isoforms of PI3 $\mathrm{K}^{[212]}$, postulated to impair the function of tumour-supporting CD4+ T cells and macrophages within the microenvironment through concomitant $\gamma$ isoform inhibition ${ }^{[213-215]}$. In vitro duvelisib interrupts AKT signalling within CLL cells stimulated by CD40L/IL-2/IL-10, CLL cell homing and intracellular signalling downstream of the $\mathrm{BCR}^{[216]}$. In a Phase I clinical trial, duvelisib attained an ORR of 56\% (1 CR) in patients with R/R CLL and $83 \%$ in TN CLL, but was complicated by frequent toxicity (Grade $\geq$ III in $84 \%$ of patients), including diarrhea and transaminitis ${ }^{[212]}$. In a Phase III trial comparing duvelisib to ofatumumab in R/R CLL, the dual PI3K inhibitor showed superior ORR ( $74 \% v s .45 \%)$ and PFS (13 months vs. 10 months), but a high rate of severe adverse effects (Grade $\geq$ III in $87 \%$ of patients: neutropenia $30 \%$, diarrhea $15 \%$, pneumonia $14 \%$ and anaemia $13 \%$ ). Toxicity was the most common reason for discontinuing duvelisib (35\% of cessations $v s$. $22 \%$ due to progressive disease $)^{[217]}$. Overall, the modest PFS benefit and frequent toxicity that compromises idelalisib seems likely to similarly challenge the potential of duvelisib. Umbralisib (TGR-1202) is another $\mathrm{PI} 3 \mathrm{~K}$ inhibitor with greater selectivity for the $\mathrm{p} 100 \delta$ isoform as well as action against casein kinase-1e. In a Phase I study enrolling 90 patients with R/R CLL and non-Hodgkin lymphoma, serious adverse effects were largely haematological, although one case of severe colitis occurred, and $37 \%$ of patients had an objective response $^{[218]}$. Preliminary data suggest that umbralisib may have a favourable toxicity profile and may be safely co-administered with ibrutinib or venetoclax with or without an anti-CD20 monoclonal; however, the follow up for these cohorts is short and serous immunological adverse events have occurred ${ }^{[219-221]}$. Longer-term follow up of alternative PI3K inhibitors will be required to determine whether they can indeed overcome the disadvantageous toxicities that vex idelalisib deliverability.

Another strategy to enhance the efficacy of BCR inhibitors has been to combine them with CIT regimens. In a Phase III study comparing idelalisib to placebo in combination with bendamustine-rituximab for R/R CLL, idelalisib combination was associated with prolonged PFS (median PFS 21 months vs. 11 months); however, it was associated with an increased rate of serious adverse effects (68\%vs. 44\%) and early discontinuation due to adverse event $(27 \% \text { vs. } 13 \%)^{[222]}$. Although limited by cross study comparison, the PFS achieved by idelalisib-bendamustine-rituximab is similar to reports of idelalisib combined with rituximab or ofatumumab in patients with $\mathrm{R} / \mathrm{R} \mathrm{CLL}^{[16,194,195,203]}$. In a Phase I study, longer PFS was observed in patients receiving idelalisib-rituximab than idelalisib-bendamustine \pm rituximab, although numbers were small $^{[202]}$. Overall, these data cast doubt over the utility of combining idelalisib with chemotherapy in the R/ $\mathrm{R}$ setting. Similarly, the HELIOS trial compared ibrutinib to placebo in combination with bendamustinerituximab in patients with R/R CLL, with ibrutinib combination demonstrating superior depth of response, PFS (36-month PFS 68\% vs. 14\%) and OS (36 months OS 82\% vs. 73\%); however, Grade III/IV treatment emergent adverse effects (TEAEs) occurred in $89 \%$ of patients treated with triplet combination, with death due to TEAEs in $10 \%$ of patients ${ }^{[149,223]}$. Moreover, the 36 -month PFS and OS observed with ibrutinib 
monotherapy in the RESONATE trial was $59 \%$ and $74 \%$, respectively, suggesting that the yield of adding bendamustine may be low $^{[96]}$. Although cross-trial comparison is unreliable, it remains unclear whether the addition of chemotherapy to novel agents in the R/R setting offers prolonged survival compared to novel agents alone or combined with anti-CD20 monoclonal antibodies. In the frontline setting, duvelisib has been combined with FCR for treatment of young, fit patients in a Phase Ib study, achieving BM uMRD status in 21 out of $26(81 \%)$ patients, although severe immunological toxicities were observed ${ }^{[224]}$. Early data from a comparable Phase II trial adding ibrutinib to FCR in fit young patients with untreated CLL also demonstrated a high rate of BM uMRD attainment $(84 \%)^{[225]}$, likely improved on historical outcomes with FCR alone ${ }^{[226]}$. One patient suffered from sudden cardiac death at 17 months, potentially attributable to ibrutinib ${ }^{[225]}$. Although these data suggest idelalisib or ibrutinib can enhance the depth of response to CIT, longer-term follow up and randomised studies will be required to determine whether the addition of chemotherapy, with likely enhanced toxicity, offers improved outcomes over targeted agents alone or in combination with each other.

\section{Summary: idelalisib}

Although a valuable component of the therapeutic armamentarium against CLL, inferior disease control and frequent toxicity have limited the role of idelalisib in clinical practice. We would recommend venetoclax- or ibrutinib-based therapy over idelalisib for most patients with CLL, reserving idelalisibrituximab therapy for patients who have disease resistant to both agents. Later generation PI3K inhibitors may have a role within fixed duration targeted therapy combination.

\section{CONCLUSIONS AND FUTURE DIRECTIONS}

Targeted agents have dramatically changed the therapeutic options and prognosis of patients with CLL. Most patients with CLL today are best treated with a targeted agent, with particular benefit in patients with traditional high-risk disease features or comorbidities that previously precluded effective therapy. Longer-term follow up may ultimately resolve the question of best first therapy in young fit patients with mutated IGHV. Older patients with mutated IGVH also have a long PFS and time to next therapy with chlorambucil-obinutuzumab and this may remain a reasonable or even preferred approach in settings where the cumulative community and personal cost of very-long-term ibrutinib is prohibitive, or cardiac toxicities are a concern. Unfortunately, another substantial pitfall of all three approved targeted agents is their significant cost, with an estimated monthly price of $\sim 11,000$ USD for ibrutinib, 9000 USD for venetoclax and $\sim 8000$ USD for idelalisib ${ }^{[22]}$. The escalating costs of continuous targeted agent therapy threaten to stress societal and patient finances, but may be mitigated with the use of time-limited combination regimens. With maturing experience using continuous single agent targeted therapy, several common themes emerge. It is clear that indefinite BCR pathway inhibitor therapy is ultimately poorly tolerated by many patients, although alternative agents with different selectivity may improve deliverability. Nevertheless, even for patients who can tolerate long-term therapy with targeted agents, the emergence of resistant disease is common, at least in the R/R setting. For both venetoclax and ibrutinib, the presence of mutations in TP53 or NOTCH1, and complex karyotype, portend the development of earlier resistant disease, despite high initial response rates. BTK/PLCG2 mutations are present in the majority of patients relapsing on ibrutinib, whereas $B C L 2$ mutations account for only a portion of venetoclax resistance, with as yet unknown, but likely polyclonal, mechanisms driving progression in any individual patient. Pre-clinical evidence implicating the CLL microenvironment in venetoclax resistance provides a compelling case for ibrutinib-venetoclax combination. Indeed, it appears that ibrutinib and venetoclax are each an effective therapy for disease resistant to the other. Together, toxicities, inevitable resistance, the escalating cost of indefinite therapy and likely anti-neoplastic synergy form a robust argument for time-limited combination therapy, although long-term follow up will be required to evaluate this strategy. To date, the MURANO and CLL14 trials represent the most established steps toward time-limited combination, achieving 
Table 4. Targeted therapy combination trials with a strategy for treatment cessation

\begin{tabular}{|c|c|c|c|c|c|}
\hline Study & Patient group & Fixed regimen & $\begin{array}{c}\text { Cessation/continuation } \\
\text { strategy }\end{array}$ & Preliminary data & $\begin{array}{l}\text { Latest follow } \\
\text { up }\end{array}$ \\
\hline $\begin{array}{l}\text { Tam et al. }^{[228]} \\
\text { CAPTIVATE } \\
\text { NCT02910583 } \\
\text { (ibrutinib- } \\
\text { venetoclax) }\end{array}$ & $\begin{array}{l}\mathrm{TN},<70 \text { years } \\
(n=164)\end{array}$ & $\begin{array}{l}\text { IBR for cycle 1-3 } \\
\text { IBR + VEN for } \\
\text { cycle 4-15 }\end{array}$ & $\begin{array}{l}\text { BM uMRD or -pos after } \\
\text { cycle } 15 \text { randomized to } \\
\text { placebo or IBR* }\end{array}$ & $\begin{array}{l}\text { After } 12 \text { combination cycles: } \\
\text { PB uMRD 75\% } \\
\text { BM uMRD 72\% } \\
1 \text { case laboratory TLS } \\
\text { AEs leading to } \\
\text { discontinuation in } 7 \%\end{array}$ & $\begin{array}{l}\text { Median } 15 \text { (< } \\
\text { 1-20) months }\end{array}$ \\
\hline $\begin{array}{l}\text { Lampson et al. }{ }^{[229]} \\
\text { NCT03580928 } \\
\text { (acalabrutinib- } \\
\text { venetoclax- } \\
\text { obinutuzumab) }\end{array}$ & $\begin{array}{l}\mathrm{TN} \\
(n=37)\end{array}$ & $\begin{array}{l}\text { ACAL for cycle } \\
1-24+G \text { cycles } \\
2-7+\text { VEN cycle } \\
4-24\end{array}$ & $\begin{array}{l}\text { Patient may cease therapy } \\
\text { at cycle } 15 \text { or cycle } 24 \text { if } \\
\text { BM UMRD CR }\end{array}$ & $\begin{array}{l}\text { After cycle } 8 \\
\text { PB uMRD } 65 \% \\
\text { BM uMRD } 50 \% \\
\text { Grade } \geq \text { III neutropenia 32\% } \\
\text { Infusion reactions } 22 \%\end{array}$ & $\begin{array}{l}\text { Median } 8 \text { (2- } \\
\text { 11) months }\end{array}$ \\
\hline $\begin{array}{l}\text { Jain et al. }{ }^{[69,230]} \\
\text { NCT02756897 } \\
\text { (ibrutinib- } \\
\text { venetoclax) }\end{array}$ & $\begin{array}{l}\text { TN } \\
\text { Del(17p), mutated } \\
\text { TP53, del(11q), } \\
\text { unmutated IGHV or } \geq \\
65 \text { years } \\
(n=80)\end{array}$ & $\begin{array}{l}\text { IBR for cycle 1-3 } \\
\text { IBR + VEN for } \\
\text { cycle 4-27 }\end{array}$ & $\begin{array}{l}\text { BM MRD-pos patients } \\
\text { after cycle } 27 \text { can continue } \\
\text { IBR }^{\star}\end{array}$ & $\begin{array}{l}\text { After cycle } 27: \\
79 \% \text { BM uMRD } \\
12 \text { patients }(15 \%) \text { off trial } \\
3 \text { cases laboratory TLS } \\
\text { Grade } \geq \text { III neutropenia } 48 \%\end{array}$ & $\begin{array}{l}\text { Median } 23 \\
\text { months }\end{array}$ \\
\hline $\begin{array}{l}\text { Jain et al. }{ }^{[231]} \\
\text { NCT02756897 } \\
\text { (ibrutinib- } \\
\text { venetoclax) }\end{array}$ & $\begin{array}{l}\mathrm{R} / \mathrm{R} \\
(n=80)\end{array}$ & $\begin{array}{l}\text { IBR for cycle 1-3 } \\
\text { IBR + VEN for } \\
\text { cycle } 4-27\end{array}$ & $\begin{array}{l}\text { BM MRD-pos patients } \\
\text { after cycle } 27 \text { can continue } \\
\text { IBR* }^{\star}\end{array}$ & $\begin{array}{l}\text { After cycle } 27 \text { : } \\
67 \% \text { BM uMRD } \\
19 \% \text { off trial, mostly due to } \\
\text { toxicity }\end{array}$ & $\begin{array}{l}\text { Median } 22 \\
\text { months }\end{array}$ \\
\hline $\begin{array}{l}\text { Hillmen et al. }{ }^{[68]} \\
\text { CLARITY } \\
\text { ISCRTN13751862 } \\
\text { (ibrutinib- } \\
\text { venetoclax) }\end{array}$ & $\begin{array}{l}\mathrm{R} / \mathrm{R} \\
(n=53)\end{array}$ & $\begin{array}{l}\text { IBR for } 2 \text { cycles } \\
\text { IBR+VEN after } \\
\text { cycle } 2\end{array}$ & $\begin{array}{l}\text { PB/BM uMRD at cycle } 8: \\
\text { cease therapy after cycle } \\
\text { 14; PB/BM uMRD between } \\
\text { cycle 14-26: cease therapy } \\
\text { after cycle } 26 \\
\text { MRD-pos at cycle } \\
\text { 26: continue IBR } \\
\text { monotherapy* }\end{array}$ & $\begin{array}{l}\text { After } 12 \text { months } \\
\text { combination: } \\
\text { PB uMRD 53\% } \\
\text { BM uMRD } 36 \% \\
34 \text { episodes grade } \geq \text { III } \\
\text { neutropenia } \\
\text { 1 case laboratory TLS }\end{array}$ & $\begin{array}{l}\text { Median } 21 \\
\text { months }\end{array}$ \\
\hline $\begin{array}{l}\text { Rogers et al. }{ }^{[232]} \\
\text { NCT02427451 } \\
\text { (ibrutinib- } \\
\text { venetoclax- } \\
\text { obinutuzumab) }\end{array}$ & $\begin{array}{l}\mathrm{R} / \mathrm{R} \\
(n=12)\end{array}$ & $\begin{array}{l}\text { G cycle } 1-8+\text { IBR } \\
\text { cycles } 2-14+\text { VEN } \\
\text { cycle } 3-14\end{array}$ & $\begin{array}{l}\text { After cycle 14, } \\
\text { can continue IBR } \\
\text { monotherapy }\end{array}$ & $\begin{array}{l}\text { After cycle 14: } \\
\text { PB uMRD 100\% } \\
\text { BM uMRD 50\% } \\
\text { Grade } \geq \text { III neutropenia 33\% } \\
\text { Infusion reaction } 83 \%\end{array}$ & $\begin{array}{l}\text { Median } 24 \\
\text { months }\end{array}$ \\
\hline $\begin{array}{l}\text { Rogers et al. } \\
\text { (ibrutinib- } \\
\text { venetoclax- } \\
\text { obinutuzumab) }\end{array}$ & $\begin{array}{l}\mathrm{R} / \mathrm{R}(n=25) \\
\mathrm{TN}(n=25)\end{array}$ & $\begin{array}{l}\text { G cycle 1-8 + IBR } \\
\text { cycles 2-14 + VEN } \\
\text { cycle 3-14 }\end{array}$ & $\begin{array}{l}\text { After cycle } 14, \\
\text { can continue IBR } \\
\text { monotherapy }\end{array}$ & $\begin{array}{l}\text { Mid therapy, } 16 / 23 \text { (70\%) } \\
\text { BM uMRD } \\
\text { Grade } \geq 3 \text { neutropenia 56\%, } \\
\text { Grade } \geq 3 \text { HTN in } 32 \% \\
1 \text { fatal neutropenic colitis }\end{array}$ & $\begin{array}{l}\text { Median } \\
18(0-25) \\
\text { months }\end{array}$ \\
\hline $\begin{array}{l}\text { Niemann et al. }{ }^{[234]} \\
\text { VISION/HOVON } \\
141 \\
\text { NCT03226301 } \\
\text { (ibrutinib- } \\
\text { venetoclax) }\end{array}$ & $\begin{array}{l}\mathrm{R} / \mathrm{R} \\
(n=230)\end{array}$ & $\begin{array}{l}\text { IBR for cycle } 1-2 \\
\text { IBR + VEN for } \\
\text { cycle 3-15 }\end{array}$ & $\begin{array}{l}\text { > PR and BM uMRD after } \\
\text { cycle } 15 \text { randomized } \\
\text { to observation or IBR } \\
\text { monotherapy* } \\
\text { MRD recrudescence } \\
\text { retreated with combination }\end{array}$ & $\begin{array}{l}\text { After } 15 \text { cycles: } \\
\text { PB uMRD 55\% } \\
\text { BM uMRD 39\% } \\
\text { AEs leading to } \\
\text { discontinuation in } 4 \%\end{array}$ & $\begin{array}{l}51 \text { patients } \\
\text { treated for } \\
\text { duration of } 15 \\
\text { cycles }\end{array}$ \\
\hline $\begin{array}{l}\text { Thompson et al. }{ }^{[235]} \\
\text { (ibrutinib- } \\
\text { venetoclax) }\end{array}$ & $\begin{array}{l}\geq 1 \text { year of prior IBR } \\
\text { treatment, not uMRD } \\
\text { High risk feature: } \\
\text { TP53 mutation, } \\
\text { del(17p), del(11q), CK, } \\
\text { elevated B2MG } \\
(n=35)\end{array}$ & $\begin{array}{l}\text { Add } V E N \text { to IBR } \\
\text { therapy for up to } \\
2 \text { years }\end{array}$ & $\begin{array}{l}\text { UMRD CR on two } \\
\text { assessments: discontinue } \\
\text { all therapy or continue IBR } \\
\text { monotherapy* } \\
\text { Patients MRD-pos or } \\
\text { <CR: continue IBR } \\
\text { monotherapy* }\end{array}$ & $\begin{array}{l}\text { BM uMRD 10/15 (67\%) at } \\
12 \text { months }\end{array}$ & $\begin{array}{l}15 \text { patients } \\
\text { evaluable at } \\
12 \text { months of } \\
\text { combination } \\
\text { therapy }\end{array}$ \\
\hline $\begin{array}{l}\text { Barr et al. }{ }^{[219]} \\
\text { NCT03801525 } \\
\text { (umbralisib- } \\
\text { venetoclax- } \\
\text { ublituximab) }\end{array}$ & $\begin{array}{l}\mathrm{R} / \mathrm{R} \\
(n=21)\end{array}$ & $\begin{array}{l}\text { UMBRA cycle 1-12 } \\
+ \text { UBLI cycle 1-3+ } \\
\text { VEN cycle 4-12 }\end{array}$ & $\begin{array}{l}\text { BM uMRD at cycle 12, } \\
\text { discontinue all therapy } \\
\text { BM MRD-pos at cycle } \\
\text { 12, continue UMBRA } \\
\text { monotherapy }\end{array}$ & $\begin{array}{l}4 \text { patients with BM uMRD } \\
(19 \%)\end{array}$ & $\begin{array}{l}\text { Median } 4(< \\
1-14) \text { months }\end{array}$ \\
\hline
\end{tabular}




\begin{tabular}{|c|c|c|c|c|c|}
\hline $\begin{array}{l}\text { Crombie et al. }{ }^{[236]} \\
\text { (duvelisib- } \\
\text { venetoclax) }\end{array}$ & $\begin{array}{l}\mathrm{R} / \mathrm{R} \\
(n=12)\end{array}$ & $\begin{array}{l}\text { DUV D1-7, then } \\
\text { DUV+VEN for } 12 \\
\text { cycles }\end{array}$ & $\begin{array}{l}\text { uMRD on two } \\
\text { assessments, discontinue } \\
\text { all therapy } \\
\text { Resume VEN monotherapy } \\
\text { at MRD recrudescence } \\
\text { MRD-pos, continue VEN } \\
\text { monotherapy }\end{array}$ & $\begin{array}{l}1 \text { patient with BM uMRD CR } \\
\text { Grade } \geq \text { III neutropenia } 83 \%\end{array}$ & $\begin{array}{l}\text { Median } \\
\text { number of } \\
\text { cycles } 6 \\
\text { (range 1-9) }\end{array}$ \\
\hline
\end{tabular}

Cycles are 28 days unless otherwise stated. *Continued monotherapy until death. R/R: relapsed and refractory. TN: treatment naïve; R: rituximab; CIRS: cumulative illness rating scale; $\mathrm{CrCl}$ : creatinine clearance; PR: partial response; PB UMRD: peripheral blood measurable residual disease less than $10^{-4}$; BM uMRD: bone marrow measurable residual disease less than $10^{-4}$; IBR: ibrutinib 420 mg daily; ACAL: acalabrutinib 100 mg BD; VEN: venetoclax 400 mg daily after dose escalation; G: obinutuzumab (100 mg on Day 1, 900 mg on Day 2, 1000 mg on Days 8 and 15, then 1000 mg Day 1, 28 day cycles); UBLI: ublituximab 900 mg weekly for Cycle 1, then once for Cycles 2 and 3; UMBRA: umbralisib, 600 or 800 mg daily; DUV: duvelisib 25 mg BD; progression or unacceptable toxicity; CK: complex karyotype; B2MG: beta-2-microglobulin

deep remissions for the majority of patients (PB uMRD in $62 \%$ and $76 \%$, respectively). Initial data from ibrutinib-venetoclax combination in high risk or elderly TN patients reported an ORR/CRR of 100\%/88\% after 12 cycles of combination therapy ${ }^{[69]}$, with 23 out of 29 (79\%) patients who completed 24 months of combination therapy achieving BM uMRD status ${ }^{[230]}$. Similar rates of BM uMRD achievement (73\%) have been reported after 12 cycles of ibrutinib-venetoclax treatment in younger TN patients in the CAPTIVATE study ${ }^{[228]}$. In patients with R/R CLL in the CLARITY study, at 12 months of ibrutinibvenetoclax combination, the ORR/CRR was $89 \% / 51 \%$ with $\mathrm{PB} / \mathrm{BM}$ uMRD attainment in $53 \% / 36 \%$ of patients $^{[68]}$. A Phase I trial of 12-month fixed duration venetoclax-ibrutinib-obinutuzumab in R/R patients reported an ORR/CRR of $92 \% / 42 \%$ and $50 \%$ BM uMRD at the completion of treatment, allowing half the cohort to cease therapy while MRD-positive cases continued ibrutinib monotherapy. No new toxicities have yet been identified, although infusion reactions were common $(83 \%)^{[232]}$. The same regimen in TN patients also appears safe and effective in an early report ${ }^{[233]}$. Combination of acalabrutinib-venetoclaxobinutuzumab has also demonstrated a favourable toxicity profile and 50\% BM uMRD after eight cycles (four cycles of triplet therapy) ${ }^{[229]}$. Table 4 summarises clinical trials with a strategy for time-limited combination targeted agent therapy for which preliminary data are available. Overall, venetoclax is a critical component to facilitate time-limited therapy targeting uMRD, while planned use of continuous BTK inhibitor therapy for patients with suboptimal responses is a common theme among current trials. It seems certain that durable PFS and frequent uMRD remission will become commonplace with doublet or triplet targeted agent regimens. Extended follow up will be required to determine if any patients with CLL will achieve durable uMRD remissions with combination targeted therapy as seen with frontline FCR in IGHV mutated disease. As we migrate into a new paradigm of time-limited combination therapy, new questions emerge regarding the optimal combination, duration of therapy, predictors of safe cessation and possibility for retreatment if the scourge of resistant disease is rendered infrequent.

\section{DECLARATIONS}

\section{Acknowledgments}

The authors thank all the patients, family members, and staff who participated in the studies.

\section{Authors' contributions}

Designed and wrote this review: Lew TE, Anderson MA, Seymour JF

\section{Availability of data and materials}

Not applicable.

\section{Financial support and sponsorship}

None. 


\section{Conflicts of interest}

TEL and MAA are employees of the Walter and Eliza Hall Institute of Medical Research, which receives milestone and royalty payments related to venetoclax. TEL and MAA are recipients of a share in royalty payments paid to the Walter and Eliza Hall Institute of Medical Research. JFS receives research funding from AbbVie, Genentech, Celgene, and Janssen; and is an advisory board member and has received honoraria from AbbVie, Acerta, Celgene, Genentech, Janssen, Roche, Sunesis, and Takeda. MAA has received honoraria from AbbVie and CSL. TEL has received honoraria from AbbVie.

\section{Ethical approval and consent to participate}

Not applicable.

\section{Consent for publication}

Not applicable.

\section{Copyright}

(c) The Author(s) 2020.

\section{REFERENCES}

1. Siegel RL, Miller KD, Jemal A. Cancer statistics, 2019. CA Cancer J Clin 2019;69:7-34.

2. Hallek M, Fischer K, Fingerle-Rowson G, Fink AM, Busch R, et al. Addition of rituximab to fludarabine and cyclophosphamide in patients with chronic lymphocytic leukaemia: A randomised, open-label, phase 3 trial. Lancet 2010;376:1164-74.

3. Fischer K, Cramer P, Busch R, Bottcher S, Bahlo J, et al. Bendamustine in combination with rituximab for previously untreated patients with chronic lymphocytic leukemia: A multicenter phase II trial of the german chronic lymphocytic leukemia study group. J Clin Oncol 2012;30:3209-16.

4. Goede V, Fischer K, Busch R, Engelke A, Eichhorst B, et al. Obinutuzumab plus chlorambucil in patients with cll and coexisting conditions. N Engl J Med 2014;370:1101-10.

5. Goede V, Fischer K, Dyer MJ, Müller L, Smolej L. Overall survival benefit of obinutuzumab over rituximab when combined with chlorambucil in patients with chronic lymphocytic leukemia and comorbidities: final survival analysis of the CLL11 study. 23rd Congress of the European Haematology Association; 2018.

6. Goede V, Fischer K, Engelke A, Schlag R, Lepretre S, et al. Obinutuzumab as frontline treatment of chronic lymphocytic leukemia: updated results of the CLL11 study. Leukemia 2015;29:1602.

7. Strati P, Keating MJ, O’Brien SM, Ferrajoli A, Burger J, et al. Outcomes of first-line treatment for chronic lymphocytic leukemia with $17 \mathrm{p}$ deletion. Haematologica 2014;99:1350-5.

8. Balducci L. ESH-SIOG international conference on haematological malignancies in the elderly. Expert Rev Hematol 2010;3:675-7.

9. Fischer K, Cramer P, Busch R, Stilgenbauer S, Bahlo J, et al. Bendamustine combined with rituximab in patients with relapsed and/or refractory chronic lymphocytic leukemia: A multicenter phase ii trial of the german chronic lymphocytic leukemia study group. J Clin Oncol 2011;29:3559-66.

10. Laurenti L, Innocenti I, Autore F, Ciolli S, Mauro FR, et al. Chlorambucil plus rituximab as front-line therapy for elderly and/or unfit chronic lymphocytic leukemia patients: Correlation with biologically-based risk stratification. Haematologica 2017;102:e352-e5.

11. Lin KI, Tam CS, Keating MJ, Wierda WG, O'Brien S, et al. Relevance of the immunoglobulin VH somatic mutation status in patients with chronic lymphocytic leukemia treated with fludarabine, cyclophosphamide, and rituximab (FCR) or related chemoimmunotherapy regimens. Blood 2009;113:3168-71.

12. Hamblin TJ, Davis Z, Gardiner A, Oscier DG, Stevenson FK. Unmutated Ig V(H) genes are associated with a more aggressive form of chronic lymphocytic leukemia. Blood 1999;94:1848-54.

13. Krober A, Seiler T, Benner A, Bullinger L, Bruckle E, et al. V(D) mutation status, CD38 expression level, genomic aberrations, and survival in chronic lymphocytic leukemia. Blood 2002;100:1410-6.

14. O’Brien S, Furman RR, Coutre S, Flinn IW, Burger JA, et al. Single-agent ibrutinib in treatment-naive and relapsed/refractory chronic lymphocytic leukemia: A 5-year experience. Blood 2018;131:1910-9.

15. Roberts AW, Davids MS, Pagel JM, Kahl BS, Puvvada SD, et al. Targeting BCL2 with venetoclax in relapsed chronic lymphocytic leukemia. N Engl J Med 2016;374:311-22.

16. Furman RR, Sharman JP, Coutre SE, Cheson BD, Pagel JM, et al. Idelalisib and rituximab in relapsed chronic lymphocytic leukemia. N Engl J Med 2014;370:997-1007.

17. Shanafelt TD, Wang XV, Kay NE, Hanson CA, O'Brien S, et al. Ibrutinib-rituximab or chemoimmunotherapy for chronic lymphocytic leukemia. N Engl J Med 2019;381:432-43.

18. Moreno C, Greil R, Demirkan F, Tedeschi A, Anz B, et al. Ibrutinib plus obinutuzumab versus chlorambucil plus obinutuzumab in first- 
line treatment of chronic lymphocytic leukaemia (iLLUMINATE): A multicentre, randomised, open-label, phase 3 trial. Lancet Oncol 2019;20:43-56.

19. Woyach JA, Ruppert AS, Heerema NA, Zhao W, Booth AM, et al. Ibrutinib regimens versus chemoimmunotherapy in older patients wituntreated CLL. N Engl J Med 2018;379:2517-28.

20. Fischer K, Al-Sawaf O, Bahlo J, Fink AM, Tandon M, et al. Effect of fixed-duration venetoclax plus obinutuzumab on progression-free survival, and rates and duration of minimal residual disease negativity in previously untreated patients with chronic lymphocytic leukemia and comorbidities. J Clin Oncol 2019;37:7502.

21. Fischer K, Al-Sawaf O, Bahlo J, Fink AM, Tandon M, et al. Venetoclax and obinutuzumab in patients with cll and coexisting conditions. N Engl J Med 2019;380:2225-36.

22. Seymour JF, Kipps TJ, Eichhorst B, Hillmen P, D’Rozario J, et al. Venetoclax-rituximab in relapsed or refractory chronic lymphocytic leukemia. N Engl J Med 2018;378:1107-20.

23. Byrd JC, Brown JR, O'Brien S, Barrientos JC, Kay NE, et al. Ibrutinib versus ofatumumab in previously treated chronic lymphoid leukemia. N Engl J Med 2014;371:213-23.

24. Seymour EK. Rapid transitions in the standard of care for chronic lymphocytic leukemia (CLL). Oncotarget 2019;10:2484-5.

25. Thompson PA, Tam CS, O’Brien SM, Wierda WG, Stingo F, et al. Fludarabine, cyclophosphamide, and rituximab treatment achieves long-term disease-free survival in IGHV-mutated chronic lymphocytic leukemia. Blood 2016;127:303-9.

26. Chen Q, Jain N, Ayer T, Wierda WG, Flowers CR, et al. Economic burden of chronic lymphocytic leukemia in the era of oral targeted therapies in the United States. J Clin Oncol 2017;35:166-74.

27. Woyach JA, Furman RR, Liu TM, Ozer HG, Zapatka M, et al. Resistance mechanisms for the Bruton's tyrosine kinase inhibitor ibrutinib. N Engl J Med 2014;370:2286-94.

28. Blombery P, Anderson MA, Gong JN, Thijssen R, Birkinshaw RW, et al. Acquisition of the recurrent Gly101Val mutation in BCL2 confers resistance to venetoclax in patients with progressive chronic lymphocytic leukemia. Cancer Discov 2019;9:342-53.

29. Rossi D, Spina V, Gaidano G. Biology and treatment of Richter syndrome. Blood 2018;131:2761-72.

30. Anderson MA, Tam C, Lew TE, Juneja S, Juneja M, et al. Clinicopathological features and outcomes of progression of CLL on the BCL2 inhibitor venetoclax. Blood 2017;129:3362-70.

31. Maddocks KJ, Ruppert AS, Lozanski G, Heerema NA, Zhao W, et al. Etiology of ibrutinib therapy discontinuation and outcomes in patients with chronic lymphocytic leukemia. JAMA Oncol 2015;1:80-7.

32. Souers AJ, Leverson JD, Boghaert ER, Ackler SL, Catron ND, et al. ABT-199, a potent and selective BCL-2 inhibitor, achieves antitumor activity while sparing platelets. Nat Med 2013;19:202-8.

33. Moore VDG, Brown JR, Certo M, Love TM, Novina CD, et al. Chronic lymphocytic leukemia requires BCL2 to sequester prodeath BIM, explaining sensitivity to BCL2 antagonist ABT-737. J Clin Invest 2007;117:112-21.

34. Robertson LE, Plunkett W, McConnell K, Keating MJ, McDonnell TJ. Bcl-2 expression in chronic lymphocytic leukemia and its correlation with the induction of apoptosis and clinical outcome. Leukemia 1996;10:456-9.

35. Van Delft MF, Wei AH, Mason KD, Vandenberg CJ, Chen L, et al. The BH3 mimetic ABT-737 targets selective Bcl-2 proteins and efficiently induces apoptosis via Bak/Bax if Mcl-1 is neutralized. Cancer Cell 2006;10:389-99.

36. Anderson MA, Deng J, Seymour JF, Tam C, Kim SY, et al. The BCL2 selective inhibitor venetoclax induces rapid onset apoptosis of cll cells in patients via a TP53-independent mechanism. Blood 2016;127:3215-24.

37. Roberts AW, Seymour JF, Brown JR, Wierda WG, Kipps TJ, et al. Substantial susceptibility of chronic lymphocytic leukemia to BCL2 inhibition: Results of a phase I study of navitoclax in patients with relapsed or refractory disease. J Clin Oncol 2012;30:488-96.

38. Stilgenbauer S, Eichhorst B, Schetelig J, Coutre S, Seymour JF et al. Venetoclax in relapsed or refractory chronic lymphocytic leukaemia with 17p deletion: A multicentre, open-label, phase 2 study. Lancet Oncol 2016;17:768-78.

39. Rawstron AC, Bottcher S, Letestu R, Villamor N, Fazi C, et al. Improving efficiency and sensitivity: European Research Initiative in CLL (ERIC) update on the international harmonised approach for flow cytometric residual disease monitoring in CLL. Leukemia 2013;27:1429.

40. Rawstron AC, Fazi C, Agathangelidis A, Villamor N, Letestu R, et al. A complementary role of multiparameter flow cytometry and highthroughput sequencing for minimal residual disease detection in chronic lymphocytic leukemia: an European Research Initiative on CLL study. Leukemia 2016;30:929-36.

41. Rawstron AC, Villamor N, Ritgen M, Bottcher S, Ghia P, et al. International standardized approach for flow cytometric residual disease monitoring in chronic lymphocytic leukaemia. Leukemia 2007;21:956-64.

42. Stilgenbauer S, Eichhorst B, Schetelig J, Hillmen P, Seymour JF, et al. Venetoclax for patients with chronic lymphocytic leukemia with 17p deletion: Results from the full population of a phase II pivotal trial. J Clin Oncol 2018;36:1973-80.

43. Brander DM, Seymour JF, Ma S, Anderson MA, Choi MY, et al. Durability of responses on continuous therapy and following drug cessation in deep responders with venetoclax and rituximab: long-term follow-up analysis of a Phase $1 \mathrm{~b}$ study in patients with relapsed CLL. Blood 2019;134:3036.

44. Seymour JF, Ma S, Brander DM, Choi MY, Barrientos J, et al. Venetoclax plus rituximab in relapsed or refractory chronic lymphocytic leukaemia: A phase 1b study. Lancet Oncol 2017;18:230-40.

45. Coutre S, Choi M, Furman RR, Eradat H, Heffner L, et al. Venetoclax for patients with chronic lymphocytic leukemia who progressed during or after idelalisib therapy. Blood 2018;131:1704-11.

46. Jones JA, Mato AR, Wierda WG, Davids MS, Choi M, et al. Venetoclax for chronic lymphocytic leukaemia progressing after ibrutinib: An interim analysis of a multicentre, open-label, phase 2 trial. Lancet Oncol 2018;19:65-75. 
47. Flinn IW, Gribben JG, Dyer MJS, Wierda W, Maris MB, et al. Phase 1b study of venetoclax-obinutuzumab in previously untreated and relapsed/refractory chronic lymphocytic leukemia. Blood 2019;133:2765-75.

48. Seymour JF, Kipps TJ, Eichhorst B, Hillmen P, D'Rozario J, et al. Four-year analysis of MURANO study confirms sustained benefit of time-limited venetoclax-rituximab in relapsed/refractory chronic lymphocytic leukemia. Blood 2019;134:355.

49. Kater AP, Seymour JF, Hillmen P, Eichhorst B, Langerak AW, et al. Fixed duration of venetoclax-rituximab in relapsed/refractory chronic lymphocytic leukemia eradicates minimal residual disease and prolongs survival: Post-treatment follow-up of the MURANO phase III study. J Clin Oncol 2019;37:269-77.

50. Fischer K, Ritgen M, Al-Sawaf O, Robrecht S, Tandon M, et al. Quantitative analysis of minimal residual disease (MRD) shows high rates of undetectable MRD after fixed-duration chemotherapy-free treatment and serves as surrogate marker for progression-free survival: a prospective analysis of the randomized CLL14 Trial. Blood 2019;134:36.

51. Kipps TJ, Eradat H, Grosicki S, Catalano J, Cosolo W, et al. A phase 2 study of the BH3 mimetic BCL2 inhibitor navitoclax (ABT-263) with or without rituximab, in previously untreated B-cell chronic lymphocytic leukemia. Leuk Lymphoma 2015;56:2826-33.

52. Roberts AW, Advani RH, Kahl BS, Persky D, Sweetenham JW, et al. Phase 1 study of the safety, pharmacokinetics, and antitumour activity of the BCL 2 inhibitor navitoclax in combination with rituximab in patients with relapsed or refractory CD 20+ lymphoid malignancies. Br J Haematol 2015;170:669-78.

53. Böttcher S, Ritgen M, Fischer K, Stilgenbauer S, Busch RM, et al. Minimal residual disease quantification is an independent predictor of progression-free and overall survival in chronic lymphocytic leukemia: A multivariate analysis from the randomized GCLLSG CLL8 trial. J Clin Oncol 2012;30:980-8.

54. Kovacs G, Robrecht S, Fink AM, Bahlo J, Cramer P, et al. Minimal residual disease assessment improves prediction of outcome in patients with chronic lymphocytic leukemia (CLL) who achieve partial response: Comprehensive analysis of two phase III studies of the german CLL study group. J Clin Oncol 2016;34:3758-65.

55. Kwok M, Rawstron AC, Varghese A, Evans PA, O'Connor SJ, et al. Minimal residual disease is an independent predictor for 10-year survival in CLL. Blood 2016;128:2770-3.

56. Lew TE, Anderson MA, Lin VS, Handunnetti SM, Came NA, et al. Undetectable peripheral blood mrd should be the goal of venetoclax in CLL, but attainment plateaus after 24 months. Blood Adv 2020;4:165-73.

57. Davids MS, Hallek M, Wierda W, Roberts AW, Stilgenbauer S, et al. Comprehensive safety analysis of venetoclax monotherapy for patients with relapsed/refractory chronic lymphocytic leukemia. Clin Cancer Res 2018;24:4371-9.

58. AbbVie. Venclexta (venetoclax) tablets full prescribing information. 2016.

59. Howard SC, Jones DP, Pui CH. The tumor lysis syndrome. N Engl J Med 2011;364:1844-54.

60. Davids MS, Roberts AW, Seymour JF, Gerecitano JF, Kahl BS, et al. Safety, efficacy and immune effects of venetoclax $400 \mathrm{mg}$ daily in patients with relapsed chronic lymphocytic leukemia (CLL). J Clin Oncol 2017;34:7527.

61. Roberts AW, Ma S, Kipps TJ, Coutre SE, Davids MS, et al. Efficacy of venetoclax in relapsed chronic lymphocytic leukemia is influenced by disease and response variables. Blood 2019;134:111-22.

62. Del Poeta G, Biagi A, Chiarenza A, Laurenti L, Pozzo F, et al. Impaired nodal shrinkage and apoptosis lacking define the adverse independent clinical outcome of NOTCH1 mutated chronic lymphocytic leukemia patients in the age of targeted agents. Blood 2019;134:1744.

63. Blombery P. Mechanisms of intrinsic and acquired resistance to venetoclax in B-cell lymphoproliferative disease. Leuk Lymphoma 2019:1-6.

64. Adams JM, Cory S. The BCL-2 arbiters of apoptosis and their growing role as cancer targets. Cell Death Differ 2018;25:27-36.

65. Bojarczuk K, Sasi BK, Gobessi S, Innocenti I, Pozzato G, et al. BCR signaling inhibitors differ in their ability to overcome Mcl-1mediated resistance of CLL B cells to ABT-199. Blood 2016;127:3192-201

66. Davids MS, Deng J, Wiestner A, Lannutti BJ, Wang L, et al. Decreased mitochondrial apoptotic priming underlies stroma-mediated treatment resistance in chronic lymphocytic leukemia. Blood 2012;120:3501-9.

67. Thijssen R, Slinger E, Weller K, Geest CR, Beaumont T et al. Resistance to ABT-199 induced by microenvironmental signals in chronic lymphocytic leukemia can be counteracted by CD20 antibodies or kinase inhibitors. Haematologica 2015;100:e302.

68. Hillmen P, Rawstron AC, Brock K, Munoz-Vicente S, Yates FJ, et al. Ibrutinib plus venetoclax in relapsed/refractory chronic lymphocytic leukemia: The clarity study. J Clin Oncol 2019;37:2722-9.

69. Jain N, Keating M, Thompson P, Ferrajoli A, Burger J, et al. Ibrutinib and venetoclax for first-line treatment of CLL. N Engl J Med 2019;380:2095-103

70. Tausch E, Close W, Dolnik A, Bloehdorn J, Chyla B, et al. Venetoclax resistance and acquired BCL2 mutations in chronic lymphocytic leukemia. Haematologica 2019;104:e434-e7.

71. Birkinshaw RW, Gong JN, Luo CS, Lio D, White CA, et al. Structures of BCL-2 in complex with venetoclax reveal the molecular basis of resistance mutations. Nat Commun 2019;10:2385.

72. Blombery P, Thompson ER, Nguyen T, Chen X, McBean M, et al. Detection of multiple recurrent novel BCL2 mutations co-occurring with BCL2 Gly101Val in patients with chronic lymphocytic leukemia on long term venetoclax. Blood 2019;134:171.

73. Blombery P, Birkinshaw RW, Nguyen T, Gong JN, Thompson ER, et al. Characterization of a novel venetoclax resistance mutation (BCL2 Phe104Ile) observed in follicular lymphoma. Br J Haematol 2019;186:e188-91.

74. Guieze R, Liu VM, Rosebrock D, Jourdain AA, Hernandez-Sanchez M, et al. Mitochondrial reprogramming underlies resistance to BCL2 inhibition in lymphoid malignancies. Cancer Cell 2019;36:369-84 e13.

75. Herling CD, Abedpour N, Weiss J, Schmitt A, Jachimowicz RD, et al. Clonal dynamics towards the development of venetoclax resistance 
in chronic lymphocytic leukemia. Nat Commun 2018;9:727.

76. Brown JR, Davids MS, Chang J, Ma S, Biondo J, et al. Outcomes of ibrutinib therapy in ibr-naïve patients with chronic lymphocytic leukemia progressing after venetoclax. Blood 2019;134:4320.

77. Greil R, Fraser G, Leber B, Marks R, Quaresmini G, et al. Efficacy and safety of ibrutinib after venetoclax treatment in ibr-naïve patients with relapsed/refractory chronic lymphocytic leukemia : follow-up of patients from the MURANO study. Blood 2018;132:5548.

78. Mato A, Roeker L, Eyre T, Jacobs R, Hill B, et al. Efficacy of therapies following venetoclax discontinuation in CLL: focus on B-cell receptor signal transduction inhibitors and cellular therapies. Blood 2019;134:502.

79. Mato AR, Thompson M, Allan JN, Brander DM, Pagel JM, et al. Real-world outcomes and management strategies for venetoclax-treated chronic lymphocytic leukemia patients in the united states. Haematologica 2018;103:1511-7.

80. Lin VS, Lew TE, Handunnetti SM, Blombery P, Nguyen T, et al. BTK inhibitor therapy is effective in patients with CLL resistant to venetoclax. Blood 2020; [Epub ahead of print].

81. Roeker L, Brown JR, Dreger P, Lahoud O, Eyre T, et al. Allogeneic stem cell transplantation for chronic lymphocytic leukemia in the era of novel agents. Blood 2019;134:3321.

82. Honigberg LA, Smith AM, Sirisawad M, Verner E, Loury D, et al. The Bruton tyrosine kinase inhibitor PCI-32765 blocks B-cell activation and is efficacious in models of autoimmune disease and B-cell malignancy. Proc Natl Acad Sci USA 2010;107:13075-80.

83. Craxton A, Jiang A, Kurosaki T, Clark EA. Syk and Bruton's tyrosine kinase are required for B cell antigen receptor-mediated activation of the kinase Akt. J Biol Chem 1999;274:30644-50.

84. Herman SE, Gordon AL, Hertlein E, Ramanunni A, Zhang X, et al. Bruton tyrosine kinase represents a promising therapeutic target for treatment of chronic lymphocytic leukemia and is effectively targeted by PCI-32765. Blood 2011;117:6287-96.

85. Petro JB, Khan WN. Phospholipase C- $\gamma 2$ couples Bruton's tyrosine kinase to the NF-kB signaling pathway in B lymphocytes. J Biol Chem 2001;276:1715-9.

86. Petro JB, Rahman SJ, Ballard DW, Khan WN. Bruton's tyrosine kinase is required for activation of IкB kinase and nuclear factor $\kappa \mathrm{B}$ in response to B cell receptor engagement. J Exp Med 2000;191:1745-54.

87. de Gorter DJ, Beuling EA, Kersseboom R, Middendorp S, van Gils JM, et al. Bruton's tyrosine kinase and phospholipase Cgamma2 mediate chemokine-controlled B cell migration and homing. Immunity 2007;26:93-104.

88. Niemann CU, Herman SE, Maric I, Gomez-Rodriguez J, Biancotto A, et al. Disruption of in vivo chronic lymphocytic leukemia tumormicroenvironment interactions by ibrutinib-findings from an investigator-initiated phase II study. Clin Cancer Res 2016;22:1572-82.

89. Byrd JC, Furman RR, Coutre SE, Flinn IW, Burger JA, et al. Targeting BTK with ibrutinib in relapsed chronic lymphocytic leukemia. N Engl J Med 2013;369:32-42.

90. Ahn IE, Farooqui MZH, Tian X, Valdez J, Sun C, et al. Depth and durability of response to ibrutinib in CLL: 5-year follow-up of a phase 2 study. Blood 2018;131:2357-66.

91. Farooqui MZ, Valdez J, Martyr S, Aue G, Saba N, et al. Ibrutinib for previously untreated and relapsed or refractory chronic lymphocytic leukaemia with TP53 aberrations: A phase 2, single-arm trial. Lancet Oncol 2015;16:169-76.

92. O'Brien S, Furman RR, Coutre SE, Sharman JP, Burger JA, et al. Ibrutinib as initial therapy for elderly patients with chronic lymphocytic leukaemia or small lymphocytic lymphoma: an open-label, multicentre, phase 1b/2 trial. Lancet Oncol 2014;15:48-58.

93. Mato AR, Nabhan C, Thompson MC, Lamanna N, Brander DM, et al. Toxicities and outcomes of 616 ibrutinib-treated patients in the united states: A real-world analysis. Haematologica 2018;103:874-9.

94. Jones J, Mato A, Coutre S, Byrd JC, Furman RR, et al. Evaluation of 230 patients with relapsed/refractory deletion 17p chronic lymphocytic leukaemia treated with ibrutinib from 3 clinical trials. Br J Haematol 2018;182:504-12.

95. Brown JR, Hillmen P, O’Brien S, Barrientos JC, Reddy NM, et al. Extended follow-up and impact of high-risk prognostic factors from the phase 3 RESONATE study in patients with previously treated CLL/SLL. Leukemia 2018;32:83-91.

96. Munir T, Brown JR, O’Brien S, Barrientos JC, Barr PM, et al. Final analysis from resonate: Up to six years of follow-up on ibrutinib in patients with previously treated chronic lymphocytic leukemia or small lymphocytic lymphoma. Am J Hematol 2019.

97. Barr PM, Robak T, Owen C, Tedeschi A, Bairey O et al. Sustained efficacy and detailed clinical follow-up of first-line ibrutinib treatment in older patients with chronic lymphocytic leukemia: Extended phase 3 results from RESONATE-2. Haematologica 2018;103:1502-10.

98. Burger JA, Tedeschi A, Barr PM, Robak T, Owen C, et al. Ibrutinib as initial therapy for patients with chronic lymphocytic leukemia. N Engl J Med 2015;373:2425-37.

99. O'Brien S, Jones JA, Coutre SE, Mato AR, Hillmen P, et al. Ibrutinib for patients with relapsed or refractory chronic lymphocytic leukaemia with 17p deletion (RESONATE-17): A phase 2, open-label, multicentre study. Lancet Oncol 2016;17:1409-18.

100. Jain P, Keating MJ, Wierda WG, Sivina M, Thompson PA, et al. Long-term follow-up of treatment with ibrutinib and rituximab in patients with high-risk chronic lymphocytic leukemia. Clin Cancer Res 2017;23:2154-8.

101. Burger JA, Keating MJ, Wierda WG, Hartmann E, Hoellenriegel J, et al. Safety and activity of ibrutinib plus rituximab for patients with high-risk chronic lymphocytic leukaemia: A single-arm, phase 2 study. Lancet Oncol 2014;15:1090-9.

102. Jaglowski SM, Jones JA, Nagar V, Flynn JM, Andritsos LA, et al. Safety and activity of BTK inhibitor ibrutinib combined with ofatumumab in chronic lymphocytic leukemia: A phase 1b/2 study. Blood 2015;126:842-50.

103. Abrisqueta P, González-Barca E, Ferra CM, Herranz ER, Fernandez M, et al. Preliminary results of ibrutinib followed by ofatumumab consolidation in previously untreated patients with chronic lymphocytic leukemia: GELLC7 trials from the spanish group of CLL (GELLC). Blood 2019;134:4296.

104. Shanafelt TD, Wang V, Kay NE, Hanson CA, O’Brien SM, et al. ibrutinib and rituximab provides superior clinical outcome compared to FCR in younger patients with chronic lymphocytic leukemia : extended follow-up from the E1912 trial. Blood 2019;134:33. 
105. Burger JA, Sivina M, Jain N, Kim E, Kadia T, et al. Randomized trial of ibrutinib vs ibrutinib plus rituximab in patients with chronic lymphocytic leukemia. Blood 2019;133:1011-9.

106. Borge M, Belen Almejun M, Podaza E, Colado A, Fernandez Grecco H, et al. Ibrutinib impairs the phagocytosis of rituximab-coated leukemic cells from chronic lymphocytic leukemia patients by human macrophages. Haematologica 2015;100:e140-2.

107. Da Roit F, Engelberts PJ, Taylor RP, Breij EC, Gritti G, et al. Ibrutinib interferes with the cell-mediated anti-tumor activities of therapeutic CD20 antibodies: Implications for combination therapy. Haematologica 2015;100:77-86.

108. Kohrt HE, Sagiv-Barfi I, Rafiq S, Herman SE, Butchar JP, et al. Ibrutinib antagonizes rituximab-dependent NK cell-mediated cytotoxicity. Blood 2014;123:1957-60.

109. Pavlasova G, Borsky M, Seda V, Cerna K, Osickova J, et al. Ibrutinib inhibits CD20 upregulation on CLL B cells mediated by the CXCR4/SDF-1 axis. Blood 2016;128:1609-13.

110. Golay J, Ubiali G, Introna M. The specific Bruton tyrosine kinase inhibitor acalabrutinib (ACP-196) shows favorable in vitro activity against chronic lymphocytic leukemia B cells with CD20 antibodies. Haematologica 2017;102:e400-3.

111. Woyach JA, Rogers KA, Bhat SA, Blachly JS, Jianfar M, et al. Acalabrutinib with obinutuzumab (Ob) in treatment-naive (TN) and relapsed/refractory (R/R) chronic lymphocytic leukemia (CLL): three-year follow-up. J Clin Oncol 2019;37:7500.

112. Byrd JC, Wierda WG, Schuh A, Devereux S, Chaves JM, et al. Acalabrutinib monotherapy in patients with relapsed/refractory chronic lymphocytic leukemia: updated results from the phase 1/2 ACE-CL-001 study. Blood 2017;130:498.

113. Sharman JP, Banerji V, Fogliatto LM, Herishanu Y, Munir T, et al. ELEVATE TN: Phase 3 study of acalabrutinib combined with obinutuzumab $(\mathrm{O})$ or alone vs $\mathrm{O}$ plus chlorambucil in patients with treatment-naive chronic lymphocytic leukemia (CLL). Blood 2019;134:31.

114. Alduaij W, Ivanov A, Honeychurch J, Cheadle EJ, Potluri S, et al. Novel type II anti-CD20 monoclonal antibody (GA101) evokes homotypic adhesion and actin-dependent, lysosome-mediated cell death in B-cell malignancies. Blood 2011;117:4519-29.

115. Dalle S, Reslan L, Besseyre de Horts T, Herveau S, Herting F, et al. Preclinical studies on the mechanism of action and the anti-lymphoma activity of the novel anti-CD20 antibody GA101. Mol Cancer Ther 2011;10:178-85.

116. Herter S, Herting F, Mundigl O, Waldhauer I, Weinzierl T, et al. Preclinical activity of the type II CD20 antibody GA101 (obinutuzumab) compared with rituximab and ofatumumab in vitro and in xenograft models. Mol Cancer Ther 2013;12:2031-42.

117. Mössner E, Brünker P, Moser S, Püntener U, Schmidt C, et al. Increasing the efficacy of CD20 antibody therapy through the engineering of a new type II anti-CD20 antibody with enhanced direct and immune effector cell-mediated B-cell cytotoxicity. Blood 2010;115:4393402.

118. Patz M, Isaeva P, Forcob N, Muller B, Frenzel LP, et al. Comparison of the in vitro effects of the anti-CD20 antibodies rituximab and GA101 on chronic lymphocytic leukaemia cells. Br J Haematol 2011;152:295-306.

119. Cramer P, von Tresckow J, Bahlo J, Robrecht S, Langerbeins P, et al. Bendamustine followed by obinutuzumab and venetoclax in chronic lymphocytic leukaemia (CLL2-BAG): Primary endpoint analysis of a multicentre, open-label, phase 2 trial. Lancet Oncol 2018;19:121528.

120. von Tresckow J, Cramer P, Bahlo J, Robrecht S, Langerbeins P, et al. CLL2-BIG: Sequential treatment with bendamustine, ibrutinib and obinutuzumab (GA101) in chronic lymphocytic leukemia. Leukemia 2019;33:1161-72.

121. Sun C, Tian X, Lee YS, Gunti S, Lipsky A, et al. Partial reconstitution of humoral immunity and fewer infections in patients with chronic lymphocytic leukemia treated with ibrutinib. Blood 2015;126:2213-9.

122. Long M, Beckwith K, Do P, Mundy BL, Gordon A et al. Ibrutinib treatment improves T cell number and function in CLL patients. J Clin Invest 2017;127:3052-64.

123. Dubovsky JA, Beckwith KA, Natarajan G, Woyach JA, Jaglowski S, et al. Ibrutinib is an irreversible molecular inhibitor of ITK driving a TH1-selective pressure in T lymphocytes. Blood 2013;122:2539-49.

124. Fraietta JA, Beckwith KA, Patel PR, Ruella M, Zheng Z, et al. Ibrutinib enhances chimeric antigen receptor T-cell engraftment and efficacy in leukemia. Blood 2016;127:1117-27.

125. Gauthier J, Hirayama AV, Hay KA, Li D, Lymp J, et al. Efficacy and toxicity of CD19-specific chimeric antigen receptor T-cells alone or in combination with ibrutinib for relapsed and/or refractory CLL. Biol Blood Marrow Transplant 2019;25:S9-10.

126. Gill SI, Vides V, Frey NV, Metzger S, O’Brien M, et al. Prospective clinical trial of anti-CD19 CAR T cells in combination with ibrutinib for the treatment of chronic lymphocytic leukemia shows a high response rate. Blood 2018;132:298.

127. Baptista MJ, Baskar S, Keyvanfar K, Gaglione EM, Ahn IE, et al. Patients with chronic lymphocytic leukemia treated with ibrutinib show expansion of T-cell clonotypes composed of antitumor cytotoxic CD8+ T-cells. Blood 2019;134:3030.

128. Bercusson A, Colley T, Shah A, Warris A, Armstrong-James D. Ibrutinib blocks Btk-dependent NF-kB and NFAT responses in human macrophages during Aspergillus fumigatus phagocytosis. Blood 2018;132:1985-8.

129. Ahn IE, Jerussi T, Farooqui M, Tian X, Wiestner A, et al. Atypical pneumocystis jirovecii pneumonia in previously untreated patients with CLL on single-agent ibrutinib. Blood 2016;128:1940-3.

130. Baron M, Zini JM, Challan Belval T, Vignon M, Denis B, et al. Fungal infections in patients treated with ibrutinib: Two unusual cases of invasive aspergillosis and cryptococcal meningoencephalitis. Leuk Lymphoma 2017;58:2981-2.

131. Chan TS, Au-Yeung R, Chim CS, Wong SC, Kwong YL. Disseminated fusarium infection after ibrutinib therapy in chronic lymphocytic leukaemia. Ann Hematol 2017;96:871-2.

132. Messina JA, Maziarz EK, Spec A, Kontoyiannis DP, Perfect JR. Disseminated cryptococcosis with brain involvement in patients with chronic lymphoid malignancies on ibrutinib. Open Forum Infect Dis 2017;4:ofw261.

133. Grommes C, Pastore A, Palaskas N, Tang SS, Campos C, et al. Ibrutinib unmasks critical role of Bruton tyrosine kinase in primary CNS 
lymphoma. Cancer Discov 2017;7:1018-29.

134. Lionakis MS, Dunleavy K, Roschewski M, Widemann BC, Butman JA et al. Inhibition of B cell receptor signaling by ibrutinib in primary CNS lymphoma. Cancer Cell 2017;31:833-43 e5.

135. Ghez D, Calleja A, Protin C, Baron M, Ledoux MP, et al. Early-onset invasive aspergillosis and other fungal infections in patients treated with ibrutinib. Blood 2018;131:1955-9.

136. Varughese T, Taur Y, Cohen N, Palomba ML, Seo SK, et al. Serious infections in patients receiving ibrutinib for treatment of lymphoid cancer. Clin Infect Dis 2018;67:687-92.

137. Rogers KA, Mousa L, Zhao Q, Bhat SA, Byrd JC, et al. Incidence of opportunistic infections during ibrutinib treatment for B-cell malignancies. Leukemia 2019;33:2527-30.

138. Byrd JC, Harrington B, O'Brien S, Jones JA, Schuh A, et al. Acalabrutinib (ACP-196) in relapsed chronic lymphocytic leukemia. N Engl J Med 2016;374:323-32.

139. Tam CS, Trotman J, Opat S, Burger JA, Cull G, et al. Phase 1 study of the selective BTK inhibitor zanubrutinib in B-cell malignancies and safety and efficacy evaluation in CLL. Blood 2019;134:851-9.

140. Aarup K, Enggaard L, Pedersen RS, Thomsen RH, Bergmann OJ, et al. Real-world outcomes for 205 Danish patients with chronic lymphocytic leukemia treated with ibrutinib. Blood 2019;134:1767.

141. Woyach JA, Ruppert AS, Guinn D, Lehman A, Blachly JS, et al. BTKC481S-mediated resistance to ibrutinib in chronic lymphocytic leukemia. J Clin Oncol 2017;35:1437-43.

142. Kamel S, Horton L, Ysebaert L, Levade M, Burbury K, et al. Ibrutinib inhibits collagen-mediated but not ADP-mediated platelet aggregation. Leukemia 2015;29:783.

143. Levade M, David E, Garcia C, Laurent PA, Cadot S, et al. Ibrutinib treatment affects collagen and von Willebrand factor-dependent platelet functions. Blood 2014;124:3991-5.

144. Shatzel JJ, Olson SR, Tao DL, McCarty OJT, Danilov AV, et al. Ibrutinib-associated bleeding: Pathogenesis, management and risk reduction strategies. J Thromb Haemost 2017;15:835-47.

145. Brown JR, Moslehi J, O'Brien S, Ghia P, Hillmen P, et al. Characterization of atrial fibrillation adverse events reported in ibrutinib randomized controlled registration trials. Haematologica 2017;102:1796-805.

146. McMullen JR, Boey EJ, Ooi JY, Seymour JF, Keating MJ, et al. Ibrutinib increases the risk of atrial fibrillation, potentially through inhibition of cardiac PI3K-AKT signaling. Blood 2014;124:3829-30.

147. Guha A, Derbala MH, Zhao Q, Wiczer TE, Woyach JA, et al. Ventricular arrhythmias following ibrutinib initiation for lymphoid malignancies. J Am Coll Cardiol 2018;72:697-8.

148. Lampson BL, Yu L, Glynn RJ, Barrientos JC, Jacobsen ED, et al. Ventricular arrhythmias and sudden death in patients taking ibrutinib. Blood 2017;129:2581-4.

149. Chanan-Khan A, Cramer P, Demirkan F, Fraser G, Silva RS, et al. Ibrutinib combined with bendamustine and rituximab compared with placebo, bendamustine, and rituximab for previously treated chronic lymphocytic leukaemia or small lymphocytic lymphoma (HELIOS): A randomised, double-blind, phase 3 study. Lancet Oncol 2016;17:200-11.

150. Byrd JC, Jones JA, Furman RR, Stephens DM, Devereux S, Brown JR, et al. Acalabrutinib, a second-generation Bruton tyrosine kinase (BTK) inhibitor, in previously untreated chronic lymphocytic leukemia. J Clin Oncol 2016;34:15.

151. Byrd JC, Woyach JA, Furman RR, Martin P, O’Brien SM, et al. Acalabrutinib in treatment-naive chronic lymphocytic leukemia: updated results from the phase 1/2 ACE-CL-001 study. Blood 2018;132:692.

152. Rogers KA, Thompson PA, Allan JN, Coleman M, Sharman JP, et al. Phase 2 study of acalabrutinib in ibrutinib intolerant patients with relapsed/refractory chronic lymphocytic leukemia. J Clin Oncol 2019;37:15.

153. Walter HS, Rule SA, Dyer MJ, Karlin L, Jones C, et al. A phase 1 clinical trial of the selective BTK inhibitor ONO/GS-4059 in relapsed and refractory mature B-cell malignancies. Blood 2016;127:411-9.

154. Walter HS, Jayne S, Rule SA, Cartron G, Morschhauser F, et al. Long-term follow-up of patients with CLL treated with the selective Bruton's tyrosine kinase inhibitor ONO/GS-4059. Blood 2017;129:2808-10.

155. Cull G, Simpson D, Opat S, Burger J, Trotman J, et al. Treatment with the Bruton tyrosine kinase inhibitor zanubrutinib (BGB-3111) demonstrates high overall response rate and durable responses in patients with chronic lymphocytic leukemia/small lymphocytic lymphoma: updated results from a phase 1/2 trial. Blood 2019;134:500.

156. Forum UC. Ibrutinib for relapsed/refractory chronic lymphocytic leukemia: A uk and ireland analysis of outcomes in 315 patients. Haematologica 2016;101:1563-72.

157. Iskierka-Jazdzewska E, Hus M, Giannopoulos K, Madro E, Holojda J, et al. Efficacy and toxicity of compassionate ibrutinib use in relapsed/refractory chronic lymphocytic leukemia in poland: Analysis of the polish adult leukemia group (PALG). Leuk Lymphoma 2017;58:2485-8.

158. Mato AR, Timlin C, Ujjani C, Skarbnik A, Howlett C, et al. Comparable outcomes in chronic lymphocytic leukaemia (CLL) patients treated with reduced-dose ibrutinib: Results from a multi-centre study. Br J Haematol 2018;181:259-61.

159. Chen LS, Bose P, Cruz ND, Jiang Y, Wu Q, et al. A pilot study of lower doses of ibrutinib in patients with chronic lymphocytic leukemia. Blood 2018;132:2249-59.

160. O’Brien SM, Jaglowski S, Byrd JC, Bannerji R, Blum KA, et al. Prognostic factors for complete response to ibrutinib in patients with chronic lymphocytic leukemia: A pooled analysis of 2 clinical trials. JAMA Oncol 2018;4:712-6.

161. Chiodin G, Dutton D, Martino EA, Drennan S, Tracy I, et al. High surface IgM levels associate with shorter response duration and bypass of the BTK blockade during ibrutinib therapy in CLL patients. Blood 2019;134:1752. 
162. Ahn IE, Tian X, Albitar M, Herman SE, Cook EM, et al. Validation of clinical prognostic models and integration of genetic biomarkers of drug resistance in CLL patients treated with ibrutinib. Blood 2018;132:186.

163. Miller CR, Ruppert AS, Heerema NA, Maddocks KJ, Labanowska J, et al. Near-tetraploidy is associated with richter transformation in chronic lymphocytic leukemia patients receiving ibrutinib. Blood advances 2017;1:1584-8.

164. Thompson PA, O'Brien SM, Wierda WG, Ferrajoli A, Stingo F, et al. Complex karyotype is a stronger predictor than del (17p) for an inferior outcome in relapsed or refractory chronic lymphocytic leukemia patients treated with ibrutinib $\square$ based regimens. Cancer 2015;121:3612-21.

165. Jones D, Woyach JA, Zhao W, Caruthers S, Tu H, et al. PLCG2 C2 domain mutations co-occur with BTK and PLCG2 resistance mutations in chronic lymphocytic leukemia undergoing ibrutinib treatment. Leukemia 2017;31:1645-7.

166. Ahn IE, Underbayev C, Albitar A, Herman SE, Tian X, et al. Clonal evolution leading to ibrutinib resistance in chronic lymphocytic leukemia. Blood 2017;129:1469-79.

167. Burger JA, Landau DA, Taylor-Weiner A, Bozic I, Zhang H, et al. Clonal evolution in patients with chronic lymphocytic leukaemia developing resistance to btk inhibition. Nat Commun 2016;7:11589.

168. Kadri S, Lee J, Fitzpatrick C, Galanina N, Sukhanova M, et al. Clonal evolution underlying leukemia progression and Richter transformation in patients with ibrutinib-relapsed CLL. Blood Adv 2017;1:715-27.

169. Kanagal-Shamanna R, Jain P, Patel KP, Routbort M, Bueso-Ramos C, et al. Targeted multigene deep sequencing of Bruton tyrosine kinase inhibitor-resistant chronic lymphocytic leukemia with disease progression and Richter transformation. Cancer 2019;125:559-74.

170. Landau DA, Sun C, Rosebrock D, Herman SEM, Fein J, et al. The evolutionary landscape of chronic lymphocytic leukemia treated with ibrutinib targeted therapy. Nat Commun 2017;8:2185.

171. Quinquenel A, Fornecker LM, Letestu R, Ysebaert L, Fleury C, et al. Prevalence of BTK and PLCG2 mutations in a real-life CLL cohort still on ibrutinib after 3 years: a FILO group study. Blood 2019;134:641-4.

172. Woyach J, Huang Y, Rogers KA, Bhat SA, Grever MR, et al. Resistance to acalabrutinib in CLL is mediated primarily by BTK mutations. Blood 2019;134:504.

173. Handunnetti S, Tang CPS, Nguyen T, Zhou X, Thompson ER, et al. BTK Leu528Trp - a potential secondary resistance mechanism specific for patients with chronic lymphocytic leukemia treated with the next generation BTK inhibitor zanubrutinib. Blood 2019;134:170.

174. Fama R, Bomben R, Rasi S, Dal Bo M, Ciardullo C, et al. Ibrutinib-naive chronic lymphocytic leukemia lacks Bruton tyrosine kinase mutations associated with treatment resistance. Blood 2014;124:3831-3.

175. Mato AR, Hill BT, Lamanna N, Barr PM, Ujjani CS, et al. Optimal sequencing of ibrutinib, idelalisib, and venetoclax in chronic lymphocytic leukemia: Results from a multicenter study of 683 patients. Ann Oncol 2017;28:1050-6.

176. Staber PB, Jurczak W, Brugger W, Chanan-Khan A, Greil R, et al. Primary analysis of anti-CD19 tafasitamab (MOR208) treatment in combination with idelalisib or venetoclax in R/R CLL patients who failed prior BTK inhibitor therapy (COSMOS Trial). Blood 2019;134:1754.

177. Porcu P, Flinn I, Kahl BS, Horwitz SM, Oki Y, et al. Clinical activity of duvelisib (IPI-145), a phosphoinositide-3-kinase- $\delta$, $\gamma$ inhibitor, in patients previously treated with ibrutinib. Blood 2014;124:3335.

178. Awan FT, Thirman MJ, Patel-Donnelly D, Assouline S, Rao AV, et al. Entospletinib monotherapy in patients with relapsed or refractory chronic lymphocytic leukemia previously treated with b-cell receptor inhibitors: Results of a phase 2 study. Leuk Lymphoma 2019;60:1972-7.

179. Aslan B, Mahendra M, Peoples MD, Marszalek JR, Vellano CP, et al. Vecabrutinib inhibits C481 mutated Bruton's tyrosine kinase and its downstream signaling in vitro. Cancer Res 2019;79.

180. Fabian CA, Reiff SD, Guinn D, Neuman L, Fox JA, et al. SNS-062 demonstrates efficacy in chronic lymphocytic leukemia in vitro and inhibits C481S mutated bruton tyrosine kinase. Cancer Res 2017;77:1207.

181. Allan JN, Wierda WG, Patel K, O’Brien SM, Mato AR, et al. Preliminary safety, pharmacokinetic, and pharmacodynamic results from a phase $1 \mathrm{~b} / 2$ dose-escalation and cohort-expansion study of the noncovalent, reversible Bruton's tyrosine kinase inhibitor, Vecabrutinib, in B-lymphoid malignancies. Blood 2018;132:3141.

182. Brandhuber B, Gomez E, Smith S, Eary T, Spencer S, et al. LOXO-305, a next generation reversible BTK inhibitor, for overcoming acquired resistance to irreversible BTK inhibitors. Clin Lymphoma Myeloma Leuk 2018;18:S216.

183. Mato A, Flinn IW, Pagel JM, Brown JR, Cheah CY, et al. Results from a first-in-human, proof-of-concept phase 1 trial in pretreated B-Cell malignancies for LOXO-305, a next-generation, highly selective, non-covalent BTK inhibitor. Blood 2019;134:501.

184. Naeem AS, Nguy WI, Tyekucheva S, Fernandes SM, Rai V, et al. LOXO-305: Targeting C481S Bruton tyrosine kinase in patients with ibrutinib-resistant CLL. Blood 2019;134:478.

185. Johnson AR, Kohli PB, Katewa A, Gogol E, Belmont LD, et al. Battling BTK mutants with noncovalent inhibitors that overcome Cys481 and Thr474 mutations. ACS Chem Biol 2016;11:2897-907.

186. Lee SK, Xing J, Catlett IM, Adamczyk R, Griffies A, et al. Safety, pharmacokinetics, and pharmacodynamics of BMS-986142, a novel reversible BTK inhibitor, in healthy participants. Eur J Clin Pharmacol 2017;73:689-98.

187. Reiff SD, Mantel R, Smith LL, Greene JT, Muhowski EM, et al. The BTK inhibitor ARQ 531 targets ibrutinib-resistant CLL and Richter transformation. Cancer Discov 2018;8:1300-15.

188. Smith PF, Krishnarajah J, Nunn PA, Hill RJ, Karr D, et al. A Phase I trial of PRN1008, a novel reversible covalent inhibitor of Bruton's tyrosine kinase, in healthy volunteers. Br J Clin Pharmacol 2017;83:2367-76.

189. Woyach J, Stephens DM, Flinn IW, Bhat SA, Savage R, et al. Final results of phase 1, dose escalation study evaluating ARQ 531 in patients with relapsed or refractory B-cell lymphoid malignancies. Blood 2019;134:4298. 
190. Lannutti BJ, Meadows SA, Herman SE, Kashishian A, Steiner B, et al. CAL-101, a p110delta selective phosphatidylinositol-3-kinase inhibitor for the treatment of B-cell malignancies, inhibits PI3K signaling and cellular viability. Blood 2011;117:591-4.

191. Brown JR, Byrd JC, Coutre SE, Benson DM, Flinn IW, et al. Idelalisib, an inhibitor of phosphatidylinositol 3-kinase p110delta, for relapsed/refractory chronic lymphocytic leukemia. Blood 2014;123:3390-7.

192. Herman SE, Gordon AL, Wagner AJ, Heerema NA, Zhao W, et al. Phosphatidylinositol 3-kinase- $\delta$ inhibitor cal-101 shows promising preclinical activity in chronic lymphocytic leukemia by antagonizing intrinsic and extrinsic cellular survival signals. Blood 2010;116:2078-88.

193. Zelenetz AD, Lamanna N, Kipps TJ, Coutre SE, O’Brien S, et al. A phase 2 study of idelalisib monotherapy in previously untreated patients $\geq 65$ years with chronic lymphocytic leukemia or small lymphocytic lymphoma. Blood 2014;124;1986.

194. De Vos S, Leonard JP, Barrientos JC, Schreeder MT, Flinn IW, et al. A phase 1 study of the selective PI3K $\delta$ inhibitor idelalisib (GS1101 ) in combination with therapeutic anti-CD20 antibodies (rituximab or ofatumumab) in patients with relapsed or refractory chronic lymphocytic leukemia. Blood 2013;122:4180.

195. Furman RR, de Vos S, Barrientos JC, Schreeder MT, Flinn IW, et al. Long-term follow-up of a phase 1 study of idelalisib (ZYDELIG®) in combination with anti-CD20 antibodies (rituximab or ofatumumab) in patients with relapsed or refractory chronic lymphocytic leukemia. Blood 2014;124:5653.

196. Ghia P, Pluta A, Wach M, Lysak D, Kozak T, et al. Acalabrutinib versus investigator's choice of idelalisib plus rituximab or bendamustine plus rituximab in relapsed or refractory CLL: the randomised, controlled, phase 3 ASCEND trial. SSRN 2019.

197. Ali K, Soond DR, Pineiro R, Hagemann T, Pearce W, et al. Inactivation of PI3K p110delta breaks regulatory T-cell-mediated immune tolerance to cancer. Nature 2014;510:407-11.

198. Patton DT, Garden OA, Pearce WP, Clough LE, Monk CR, et al. Cutting edge: The phosphoinositide 3-kinase p110 $\delta$ is critical for the function of CD4+ CD25+ FOXP3+ regulatory T cells. J Immunol 2006;177:6598-602.

199. Gadi D, Kasar S, Griffith A, Chiu PY, Tyekucheva S, et al. Imbalance in T cell subsets triggers the autoimmune toxicity of PI3K inhibitors in CLL. Blood 20191 134:1745.

200. O'Brien S, Lamanna N, Kipps TJ, Flinn IW, Zelenetz AD, et al. Update on a phase 2 study of idelalisib in combination with rituximab in treatment-naïve patients $\geq 65$ years with chronic lymphocytic leukemia or small lymphocytic lymphoma. Blood 2014;124:1994.

201. Lampson BL, Kim HT, Davids MS, Abramson JS, Freedman AS, et al. Efficacy results of a phase 2 trial of first-line idelalisib plus ofatumumab in chronic lymphocytic leukemia. Blood Adv 2019;3:1167-74.

202. Coutre SE, Flinn IW, de Vos S, Barrientos JC, Schreeder MT, et al. Idelalisib in combination with rituximab or bendamustine or both in patients with relapsed/refractory chronic lymphocytic leukemia. HemaSphere 2018;2:e39.

203. Sharman JP, Coutre SE, Furman RR, Cheson BD, Pagel JM, et al. Second interim analysis of a phase 3 study of idelalisib (ZYDELIG®) plus rituximab for relapsed chronic lymphocytic leukemia: efficacy analysis in patient subpopulations with del (17p) and other adverse prognostic factors. Blood 2014;124:330.

204. Jones JA, Robak T, Brown JR, Awan FT, Badoux X, et al. Efficacy and safety of idelalisib in combination with ofatumumab for previously treated chronic lymphocytic leukaemia: An open-label, randomised phase 3 trial. Lancet Haematol 2017;4:e114-e26.

205. Jones JA, Robak T, Wach M, Brown JR, Menter AR, et al. Updated results of a Phase III randomized, controlled study of idelalisib in combination with ofatumumab for previously treated chronic lymphocytic leukemia. J Clin Oncol 2016;34:7515.

206. Lampson BL, Kasar SN, Matos TR, Morgan EA, Rassenti L, et al. Idelalisib given front-line for treatment of chronic lymphocytic leukemia causes frequent immune-mediated hepatotoxicity. Blood 2016;128:195-203.

207. Coutre S, Barrientos JC, Brown JR, De Vos S, Furman RR, et al. Safety of idelalisib in B-cell malignancies: Integrated analysis of eight clinical trials. J Clin Oncol 2015;33:e18030.

208. Cheah CY, Nastoupil LJ, Neelapu SS, Forbes SG, Oki Y, et al. Lenalidomide, idelalisib, and rituximab are unacceptably toxic in patients with relapsed/refractory indolent lymphoma. Blood 2015;125:3357-9.

209. Barr PM, Saylors GB, Spurgeon SE, Cheson BD, Greenwald DR, et al. Phase 2 study of idelalisib and entospletinib: Pneumonitis limits combination therapy in relapsed refractory CLL and NHL. Blood 2016;127:2411-5.

210. Ghia P, Ljungström V, Tausch E, Agathangelidis A, Scheffold A, et al. Whole-exome sequencing revealed no recurrent mutations within the PI3K pathway in relapsed chronic lymphocytic leukemia patients progressing under idelalisib treatment. Blood 2016;128:2770.

211. Scheffold A, Jebaraj BMC, Tausch E, Yahiaoui A, Dolnik A, et al. In vivo modeling of resistance to PI3K $\delta$ inhibitor treatment using E $\mu$ TCL1-Tg tumor transfer model. Blood 2016;128:190.

212. Flinn IW, O'Brien S, Kahl B, Patel M, Oki Y, et al. Duvelisib, a novel oral dual inhibitor of PI3K- $\delta$, $\gamma$, is clinically active in advanced hematologic malignancies. Blood 2018;131:877-87.

213. De Henau O, Rausch M, Winkler D, Campesato LF, Liu C, et al. Overcoming resistance to checkpoint blockade therapy by targeting PI3K gamma in myeloid cells. Nature 2016;539:443-7.

214. Kaneda MM, Messer KS, Ralainirina N, Li H, Leem CJ, et al. PI3K $\gamma$ is a molecular switch that controls immune suppression. Nature 2016;539:437.

215. Reif K, Okkenhaug K, Sasaki T, Penninger JM, Vanhaesebroeck B, et al. Cutting edge: Differential roles for phosphoinositide 3-kinases, p110gamma and p110delta, in lymphocyte chemotaxis and homing. J Immunol 2004;173:2236-40.

216. Balakrishnan K, Peluso M, Fu M, Rosin NY, Burger JA, et al. The phosphoinositide-3-kinase (PI3K)-delta and gamma inhibitor, IPI-145 (duvelisib), overcomes signals from the PI3K/AKT/S6 pathway and promotes apoptosis in CLL. Leukemia 2015;29:1811-22.

217. Flinn IW, Hillmen P, Montillo M, Nagy Z, Illes A, et al. The phase 3 DUO trial: Duvelisib vs ofatumumab in relapsed and refractory CLL/sll. Blood 2018;132:2446-55. 
218. Burris III HA, Flinn IW, Patel MR, Fenske TS, Deng C, et al. Umbralisib, a novel PI3K $\delta$ and casein kinase-1 1 inhibitor, in relapsed or refractory chronic lymphocytic leukaemia and lymphoma: An open-label, phase 1, dose-escalation, first-in-human study. Lancet Oncol 2018;19:486-96.

219. Barr PM, Hill BT, Ma S, Baran AM, Bui A, et al. A phase 1/2 study of umbralisib ublituximab and venetoclax in patients with relapsed or refractory chronic lymphocytic leukemia. Blood 2019;134:360.

220. Mato AR, Schuster SJ, Lamanna N, Flinn I, Barrientos JC, et al. A phase 2 study to assess the safety and efficacy of umbralisib (TGR 1202) in pts with CLL who are intolerant to prior BTK or PI3K $\delta$ inhibitor therapy. J Clin Oncol 2018;36:7530.

221. Nastoupil LJ, Lunning MA, Vose JM, Schreeder MT, Siddiqi T, et al. Tolerability and activity of ublituximab, umbralisib, and ibrutinib in patients with chronic lymphocytic leukaemia and non-hodgkin lymphoma: A phase 1 dose escalation and expansion trial. Lancet Haematol 2019;6:e100-e9.

222. Zelenetz AD, Barrientos JC, Brown JR, Coiffier B, Delgado J, et al. Idelalisib or placebo in combination with bendamustine and rituximab in patients with relapsed or refractory chronic lymphocytic leukaemia: Interim results from a phase 3, randomised, double-blind, placebocontrolled trial. Lancet Oncol 2017;18:297-311.

223. Fraser G, Cramer P, Demirkan F, Silva RS, Grosicki S, et al. Updated results from the phase 3 HELIOS study of ibrutinib, bendamustine, and rituximab in relapsed chronic lymphocytic leukemia/small lymphocytic lymphoma. Leukemia 2019;33:969-80.

224. Davids MS, Fisher D, Tyekucheva S, Haesook, K, McDonough M, et al. A Phase Ib/II study of duvelisib in combination with FCR for front-line therapy of younger CLL patients. EHA Annual Meeting 2018.

225. Davids MS, Brander DM, Kim HT, Tyekucheva S, Bsat J, et al. Ibrutinib plus fludarabine, cyclophosphamide, and rituximab as initial treatment for younger patients with chronic lymphocytic leukaemia: a single-arm, multicentre, phase 2 trial. Lancet Haematol 2019;6:e419-28.

226. Thompson PA, Peterson CB, Strati P, Jorgensen J, Keating MJ, et al. Serial minimal residual disease (MRD) monitoring during first-line FCR treatment for CLL may direct individualized therapeutic strategies. Leukemia 2018;32:2388-98.

227. Hilal T, Betcher JA, Leis JF. Economic impact of oral therapies for chronic lymphocytic leukemia-the burden of novelty. Curr Hematol Malig Rep 2018;13:237-43.

228. Tam CS, Siddiqi T, Allan JN, Kipps TJ, Flinn IW, et al. Ibrutinib plus venetoclax for first-line treatment of chronic lymphocytic leukemia/ small lymphocytic lymphoma: results from the MRD cohort of the phase 2 CAPTIVATE study. Blood 2019;134.

229. Lampson BL, Tyekucheva S, Crombie JL, Lim AI, Merryman RW, et al. Preliminary safety and efficacy results from a phase 2 study of acalabrutinib, venetoclax and obinutuzumab in patients with previously untreated chronic lymphocytic leukemia. Blood 2019;134:32.

230. Jain N, Keating M, Thompson P, Ferrajoli A, Burger J, et al. Combined ibrutinib and venetoclax for first-line treatment for patients with chronic lymphocytic leukemia. Blood 2019;134:34.

231. Jain N, Keating M, Thompson P, Burger J, Ferrajoli A, et al. Combined ibrutinib and venetoclax in patients with relapsed/refractory chronic lymphocytic leukemia. Blood 2019;134:359.

232. Rogers KA, Huang Y, Ruppert AS, Awan FT, Heerema NA, et al. Phase 1b study of obinutuzumab, ibrutinib, and venetoclax in relapsed and refractory chronic lymphocytic leukemia. Blood 2018;132:1568-72.

233. Rogers KA, Huang Y, Ruppert AS, Awan FT, Hoffman C, et al. Phase 2 study of combination obinutuzumab, ibrutinib, and venetoclax in treatment-naive and relapsed/refractory chronic lymphocytic leukemia. Blood 2018;132:693.

234. Niemann C, Dubois J, Kersting S, Enggaard L, Veldhuis GJ, et al. Venetoclax and ibrutinib for patients with relapsed/refractory chronic lymphocytic leukemia - 15-month safety, response and MRD evaluation: third interim analysis from the Phase II Vision HO141 trial. Blood 2019;134:4292.

235. Thompson P, Keating M, Jain N, Ferrajoli A, Kadia T, et al. Venetoclax added to ibrutinib in high-risk CLL achieves a high rate of undetectable minimal residual disease. Blood 2019;134:358.

236. Crombie J, Tyekucheva S, Savell A, Francoeur K, Choiniere M, et al. A Phase I study of duvelisib and venetoclax in patients with relapsed or refractory CLL/SLL. Blood 2019;134:1763. 